io Amma, Appa and Komala ... 
"The rare moment, is not the moment when there is something worth looking at, but the moment when we are capable of seeing." Joseph Krutch

\section{Preface}

Scientific activity must simplify and unify if the present escalation of "result producing" is not to totally obscure pertinent problems. Often during the period of this study I have wondered which I was doing. As it turns out a slight amount of simplification has been achieved. but perhaps not nearly enough.

For the rest, I am left puzzled by the philosophy of research. The clear connection between hypothesis, experiment and result was only seen post facto. Huiever, this was a rich experience in looking, and looking carefully. More than anyone else, perhaps it is the electron microscopist who should report not merely what is seen but try to observe, understand and present a unifying pattern in what is seen.

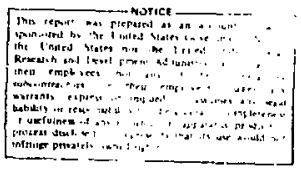




\section{CONTENTS}

Preface

Abstract............................. . . . . . . . . i

Introduction ... . . . . . . . . . . . . . . . . . . 1

Chapter 1. Summary of the Results of Previous Investigators.

Topics Investigated . . . . . . . . . . . . . . . 4

Chapter II. Specimen Preparation ................. . 14

Chapter Iil. Optimum Imaging Condition and Image Complexities. . 21

Chapter IV. Characterization of the Defects... . . . . . . . 40

Chapter V. A Model for the Presence of Interstitial Defects . . . 74 


\title{
ELECTRON MICROSCOPY STUDIES OF, ION IMPLANTED SILICON
}

\author{
Krishna Seshan
}

Inorganic Materials Research Division, Lawrence Berkeley Laboratory and Department of Materials Science and Engineering, College of Engineering; University of California, Berkeley, California 94720

Abstract

"Accidential and fortutiosis concurrance of atoms".

A. J. Temple

The nature of defects resulting from the rapid implantation of accelerated phosphorous ions into silicon and a model of how they form are riported. This involved an eiectron microscope study of the crystallographic defeces (in the $300 \AA$ size range in concentration of $10^{15} / \mathrm{cm}^{3}$ ) that form upon annealing. The annealing step, where the bombarded silican is heated to relatively low temperatures $\left(800^{\circ} \mathrm{C}\right)$, repairs the bombardment damage and in addition restors the implanted atoms to electricaliy active sites.

Studies using high $(650 \mathrm{kV})$ voltage as well as standard $(100 \mathrm{kV})$ electron microscupes showed that the images formed by these crystallographic defects are complex and that nonconventional imaging techniques are required for their characterization. Such studies revealed the optimum imaging conditions for the imaging of these defects and showed that the images of these $5 \mathrm{mill}$ defects (about $300 \AA$ or $3 \times 10^{-6} \mathrm{~cm}$ ) are sensitive to various parameters, such as the foil thickness, their position in the foil and the diffracting conditions.

Several nonconventional techniques were then lised to characterize the defects. They were found to be mostly interstitial hexagonal Frank loops lying on the four $\{111\}$ planes and a few perfect interstitial loops; these loops occurred in concentrations of about $10^{16} / \mathrm{cm}^{3}$. In addition, 
"rod like" linear defects that are shown to be interstitial are also found in concentrations of $10^{13} / \mathrm{cm}^{3}$. By varying the prior dopants in silicon it was found that the linear defects require boron for their formation. The loops show electron diffraction contrast effects which have been interpreted as arising from some of the dopant atoms being segregated to the interior of the loops.

A model is proposed to account for the interstitial defects. Attention is drawn to the fact that the number of point defects that make up the defects is of the same order as the number of implanted ions. The model predicts that only interstitial loops ought to be observed in agreement with several recent investigations.

Dislocation mudels of the loops are examined and it is shown that phosphorous ions could segreate to the Frank loops, changing their displacement vectors to $a / x[111] . \quad(x>3)$ thus exp?aining the contrast effects observed. It would also explain the relative electrica? inactivity of $\mathrm{p}^{+}$ions implanted under the conditions of this experiment-a fact that cannot be explained by present theory. 
"Make for yourself a definition or description of the thing which is presented to you so as to see distinctly what kind of a thing it is in its substance, in its nudity, in its entirety and tell yourself its proper name and the names of the things of which it has been compounded and into which it will be resolved."

Marcus Aurel ius

\section{INTRODUCTION}

lon implantation has currently become a popular method for doping semiconductors, thereby, introducing electrically active species in small quantities, in the parts per million range, to beneficially alter electrical properties. This technique is faster and permits greater control of dose and depth of the dopant species than the conventional diffusion doping technique. The depth is determined by the accelerating voltage (100 kev in the study) and the dose by the fluence used $\left(3 \times 10^{14} \mathrm{ions} / \mathrm{cm}^{2}\right)$. This rapid implantation leads to severe damage of the implanted substraie which in this study was (111) oriented silicon. The implantation damage is largely removed and a majority of the dopants are restored to electrically active sites by neating the substrate to relatively low temperatures between 500 to $800^{\circ} \mathrm{C}$ for about $15 \mathrm{~min}$ to $1 / 2 \mathrm{hr}$. A debris of small crystallographic defects in the 100 to $300 \AA$ size range, in high densities of about $10^{16}$ defects per cubic centimeter results from this annealing treatment. An investigation into the nature of these defects and the development of a model to explain how they form and affect the electrical activity of the dopants were the prime objectives of the study. 
In the first chapter it is shown that for the dose used in this study, isolated and buried damage clusters are expected. Point defect studies showing that annealing in the 100 to $490^{\circ}$ centigrade range is accompanied by the disappearance of vacancies and vacancy complexes are presented.

From this it is tempting to draw the incorrect ccnclusion that vacancy type defects are expected to form. The several electron microscopic studies of the defects formed on annealing and their contradictory descriptions are then pointed out. Lastly, the specific questions that this study undertook to resolve are set out.

In the second chapter, the implantation procedure and the techniques used to annea! the samples and prepare thin foils for electron microscopy are described.

In the third chapter experiments to determine the best imaging conditions for the defects are described. Studies with the $650 \mathrm{kV}$ Berkeley high voltage electron microscope showed that good images were obtained with second and third order reflections excited for $g=220$ and $g=111$ respectively. However, it was found that at high voltages the strong effects of several systematic beams introduce complexities in image behavior. Images of the defects disappeared anamalously in both bright and dark fields. From this study it was evident that the best resolution was obtained at. $100 \mathrm{kV}$ using nonconventionai electron microscopy: weak-beam, the symmetric weak-beam beam bright. 
field ard systematic bright field techniques.

The fourth chapter describes the results of applying such technqiues to characterize the defects. For doses where a cortinuously damaged layer is not formed, the defects that develop upon annealing are shown to be interstitial Frank loops on the four [1] planes. In addition, there are a few unfaulted loops as wel! as rod-like defects. The rods appear to be inteistitial in nature and require boron for their formation. Stereo microscopic data shows that the horizontal rods lie at the same depth as the loops whereas the inclined rods start at the level of the loops and extend upwards towards the implanted surface. They anneal from the ends in the temperature range of 700 to $750^{\circ}$ centigrade.

In the fifth chapter a madel accounting for the observed defects is presented. Contrast effects and the sensitivity of defect morphology to trace impurities are taken as evidence for interaction between the dopants and the defects. This is put forth as a feasible explanation for the poor electrical activity of foils implanted to this dose as well as the widely differing accounts of defect character in the literature. A four stage sequence involving the break up conversion and growth of interstitial clusters is propesed to account for the abserved interstitial defects. 
CHAPTER I.

SUMMARY OF THE RESULTS DF PREVIOUS INVESTIGATORS TOPICS INVESTIGATEO

1.1. Introduction . . . . . . . . . . . . . . . . 5

1.2. Summary o: Frevioss Investigations . . . . . . . . . . . . . 7

1.2.?. Type of Damage Expected. Fritical Dose Calculations 7

1.2.2. Present Evidence of Damage Annealing . . . . . . . . 9

1.2.3. Electron Microscope Studies . . . . . . . . . 10

1.3. Discussion. Topics Investigated . . . . . . . . . . . 12 
"The Science appeareg to me an claborate diabolical invention fur mystifying what was rlear, and confounding what was intelligible."

N. Sinclair

\subsection{Introduction}

The field of inn implantation has proved to be a richs ice of information in areas of radiation damage and defect studies in silicen. The incoming energenic ion depos.s its energy in the target first by ionization and then by nuclear collisions. Radiation ri mage theory has been successful in calculating the ion range distribution and describing the type of damage caused (Gibbons, 1971). Eiectron paramagnetic resonance (EPR) (Watkins, 1965) and infrared abscrption studies havebeen especially successful in elucidating the nature of the point defects produced by the collisions and their electronic nature, some of the complexes they form and their range of stabilities have been carefully mapped (Chena et al., 1966).

There are, however, several limitations to such studies since the defects have to be electrically or electronically active in order to be detected by EPR or IR spectroscopy. Of special relevance is the reported interstitial problem: "the silicon interstitial having never been identified" (Seeoar et al., 1968). The reported absence of the interstitial constitutes not only a puzzling problem, but also could lead to the incorrect conclusion that interstitials do not participate in the annealing process.

An annealing of the implanted substrate is necessary to restore the dopant atoms to electrically active sites. Depending on the typ. if damage formed, a mild anneal of $15 \mathrm{~min}$ at $600^{\circ} \mathrm{C}$ can resotre $80^{\circ}$ it the 
dopant ions to electrically active substitutional sites. However, for certsin damage conditions this figure is as low as 10 t.o 15\%. Electron microscopic examination of the silicon after the annealing treatment reveals the presence of many small defects in high densitit;.

In this thesis, the type of damage is correlated with the defec: s formed and a study is made of how the defects affect electrical conductivity during annealing. The several previous electron microscopic studies are fraught with contradictions arising in fart from the differences in interpreting complex inages of the small defects and the several factors affecting their formation. This situation together with the fact that no simple model exists to explain the origin of the defects inspired this study. 


\subsection{Summary of Previous Investigations}

\subsubsection{Type of Damage Expected. Critical Dose Calculations.}

The type of damage the substrate suffers depends on the dominant energy loss mechanism of the incoming ion. For small ions (e.g., boron) much cf the initial loss of energy is due to electronic stopping, resulting in ionization but not gross damage. As the ion slows down, its cross section for atomic collision increases until it suffers a nuclear callisior leading to massive displacement damage. This results in a damage free path followed by a zone of displaced atoms near where eact: ion came to rest. At the critical dose these iso? ated damage clusters overlap to form a buried amorphous layer. Continued irradiation then causes the buried amorphous layer to grow towards the surface (Crowder, Title 1970). For heavy ions (e.g., antimony) nuclear stopping dominates the whole range and displacements occur all along the ion path. The damage zones quickly join up to form a continuous amorphous layer extending to the surface.

The case for phosphorous is intermediate between that of boron and antimony. At $100 \mathrm{kV}$ the projected range, $R_{p}$, is $1228 \AA$ with the spread, $\Delta R_{p}$, equal to $350 \AA$ (Gibbons 1969). $R_{p}$ is usually taken as the peak position of a Gaussian profile. The dose of $\mathrm{P}^{+}$ions required to drive the silicon amorphous may be estimated (assuming no vacancy diffusion) by assuming that all the target atoms are displaced. The developmen follows that suggested by Morehead et al. 1970. That is,

$$
D o=\bar{E} n_{2} \frac{d E}{d x}{ }^{-1} \mathrm{~cm}^{-2}
$$


Whe e $D o=$ aose to drive target amorphous in ions $/ \mathrm{cm}^{2}$

$\bar{E}=$ displacement. energy for silicon $\simeq 25 \mathrm{eV}$

$n_{n}=$ number of target atoms per $\mathrm{cm}^{3}=1510^{22}$ atoms $/ \mathrm{cm}^{2}$

$\frac{d E}{d x}=$ energy independent. nuclear energy loss per unit length

$\frac{d E}{d x}$ is found by the Nielson equation

$$
\frac{d E}{d x}=7 \times 10^{8} \times g_{2} \times z_{1}^{2 / 3} \times \frac{M_{1}}{M_{1}+M_{2}} \quad \mathrm{eV} / \mathrm{cm}
$$

where $z_{1}, z_{2}, M_{1}, M_{2}$ are atomic numbers and masses of projectile and target ( $P$ and si respectively). That is,

$$
\begin{aligned}
& z_{1}=15, M_{1}=31 \text { for } P \\
& z_{2}=14, M_{2}=28 \text { for } S i
\end{aligned}
$$

and

$$
\mathrm{g}_{2} \text { is the density of silicon }=2.33 \mathrm{~g} / \mathrm{cm}^{3}
$$

giving $\frac{d E}{d x}=5.7 \times 10^{9} \mathrm{eV} / \mathrm{cm}$. Thus,

$$
\begin{aligned}
\text { Jo } & =25 \mathrm{eV} \times 5 \cdot 10^{22} \frac{\text { atoms }}{\mathrm{cm}^{3}} \times 5.1 \times i 0^{9}\left(\frac{\mathrm{eV}}{\mathrm{cm}}\right)^{-1} \\
& =2.4 \times 10^{14} \text { ions } / \mathrm{cm}^{2}
\end{aligned}
$$

This tstimate is in good agreement with the experimental results of Do $=1 \times 10^{15}$ ions $/ \mathrm{cm}^{2}$ for $280 \mathrm{keV} \mathrm{P}^{+}$(Crowder, Tittle 1970) and $3 \times 10^{14}$ ions $/ \mathrm{cm}^{2}$ for $50 \mathrm{keV} \mathrm{P}^{+}$ions (Mayer 1971). From these estimates it is reasonable to conclude that for the foils used in this study, which were $100 \mathrm{keV} \mathrm{P}^{+}$ions implanted in the $10^{14}$ range, a continuous damaged layer was not formed. A high density $\left(>5 \times 10^{11}\right.$ per $\left.\mathrm{cm}^{2}\right)$ of almost overlapping damage clusters about $70 \AA$ in diameter (Mazey, Nelson, Barnes 1968) are Expected. 
The structure of the damage cluster itself is unclear. Parsons (1965) and Mazey et al. (1968) using electron microscopic studies show that these clusters consist ed of a central disordered core surrounded by a sheath of crystalline material containing a large number of defects. Infrared absorption and EPR studies (Stein 1969, Daley 1969) show the presence of about five divacancies per implanted ion. The rest, over 95\%, not detectable by their method, they concluded were incorporated in the damage core. A volume expansion of $2 \%$ accompanies the crystalline to amorphous transition ( $T u$ et al., 1972). An expanded amorphous region is then under hydrostatic compression from the surrounding perfect crystal. The stress using Hooks law is expected to be $\sim 10^{9}$ dynes $/ \mathrm{cm}^{2}$. Comparable values $\left(2 \times 10^{9}\right.$ dynes $\left./ \mathrm{cm}^{2}\right)$ have been reported by Ernisse (1971).

The number of atoms displaced per phosphorous ion is about 1000 (Gibbons 1972). Thus $10^{22}$ atoms are expected to have been displaced per cubic centimeter. A large number of the resulting Frenkel pairs probasly annihilated. Assuming that $90 \%$ of the pairs annihilate, $10^{21}$ defects per cubic centimeter are expected.

\subsubsection{The Annealing of Damage}

Upon heating, the remaining damage repairs anis the implanted phosphorous atoms come to occupy substitutional sites. This process, occurring in the $200-600^{\circ} \mathrm{C}$ temperature range, is acrompanied by the disappearance of the divanancy and vacancy-group $V$ complexes (Mayer 1971). Thus the recovery of electrical activity has been associated with the annealing of vacancies (Mayer 1968). It is tempting to conclude from this that the divancancies collapse to give the defects observed after the annealing treatment. However, vacancy type defects are not observed after the annealing treatment (Jenkins et al. 1973, Seshan et a1. 1974). 
The percentage of the implanted ions that are electrically active after a certain given anneal depends critically on the damage. For phosphorous ion implantations, when a continuous amorphous layer is formed, a mild anneal for $15 \mathrm{~min}$ at $600-700^{\circ} \mathrm{C}$ restores almost $100 \%$ activity. When a continuous layer is not formed (dose $>10^{13}$, $<10^{75}$ ions $/ \mathrm{cm}^{2}$ ) the same anncaling treatment results in less than $15 \%$ activity. A much higher annealing temperature of $900^{\circ} \mathrm{C}$ is required to recover full electrical activity (Crowder 1960, Gibson et al. 1968).

\subsubsection{Electron Microscopy Studies}

Several electron microscopic studies of the defects formed upon anneding of ion implanted silicon in the $500-700^{\circ} \mathrm{C}$ range exist. They are, however, incomplete and advance contradictory descriptions of the defects and suggest no model for the defect formation. The defects in boron implanted silicon were first reported as vacancy type (Chadderton, Eisen 1971) assuming that they are formed from the collapse of divacancies. Another study (Bicknell, Allen i970) reported that the defects were interstitiat type.

One study of defects in phosphorous implanted silicon first reported that they were perfect loops lying in the foil plane and were interstitial type (Dovidson, Booker 1970). Others also reported the Toops as perfect but the habit planes were not determined (Tamura et al. 1971, Wu et al. 1973). Recent7y all these loops have been reported as imperfect loops (i.e., Frank loops) lying on the four \{111\} planes (Jenkins et al.1973, Madden 1973). There has also been consideratie variation in descriptions of loops morphology between workers. Linear defects were first reported as absent in phosphorous implants (Bicknell, Ailen 1970) while others 
have reported their rresece (Seshan et a7. 1972, Madden 1973).

Tamura et al. (1971) found linear defects in hot substrate phosphorous implants unly.

It was evident from this situation that a more systematic study of the nature of the defects was warrented. 


\subsection{Discussion. Topics Investigated}

From the brief review presented, it is obvious that several factors affect the annealing process; how these affect the recovery of electrical properties and influence the kind of defects produced is not completely understood. The situation in silicon is further complicated not only by the dopants in the foil prior to implantation but aiso by impurities like oxyger and carbon (present in concentrations about $10^{15} / \mathrm{cm}^{3}$ ) whose role is entirely unknown.

This ele-cron microscopic study was undertaken in order to clarify the spe:1fic problems listed below. Phosphorous and silicon ions were chosen for the bombarding species as boron implantations have been more thoroughly investigated.

Firstly, in the light of conflicting reports about the nature of the defects, a further study of defect type, habit plane and morphology was thought necessary. In order to do this the behavior of the images of these small defects were first studied and the conditions under whic the best images were obtained were determined using the low as well as the high voltage e ectron microscopes.

Secondly, the poor electrical activity of phosphorous implantations up to a dose where a continuous amorphous layer is formed (Crowder et a1., 1969) does not have a satisfactory explanation. Precipitation near the loops has been iuggested but no mechanism has been proposed (Davidsin and Booker, 1970). Attraction of the dopant to the dislocation core is a possibility (Gibbons, 1970). However, this interaction, varying as the square of the difference between the volumes of the host and impurity, is expected to be sma1l for phosphorous in silicon. 
Lastly, there is no simple model for the annealing process. It is suggested on the basis of observations that the annealing occurs via the motion of vacancies and divacancies (Cheng et al., 1966). How this results in the formation of high densities $\left(10^{13}\right.$ per $\left.\mathrm{cm}^{3}\right)$ of sma?l interstitial type dislocation loops has no simple explanation. A model to explain this result has been developed. 
$-14-$

CHAPTER II.

SPECIMEN PREPARATION

2.1. Implantation Procedure . . . . . . . . . . 15

2.2. Heat Treatment . . . . . . . . . . . . 18

2.3. Thin Foil Preparation ............. 19 


\begin{abstract}
"Unhurt amidst of war of elements, the wrecks of matter and the crash of worlds."

Addison
\end{abstract}

\title{
2.1. Implantation Procedure
}

A schematic of the ion implantation procedure is shown in Fig. 2.1. The implantation was carried out at the Fairchild Research anc. Development division. The foils were tilted $8^{\circ}$ away from the exict 111 orientation in order to minimize channeling. Ions of $\mathrm{P}^{+}$and $\mathrm{Si}^{+}$, accelerated to $100 \mathrm{keV}$ were implanted into the following chips.

1. (111) p-type (boron doped) silicon. Resistivity $0.2-8 \Omega \mathrm{cm}$

2. (111) n-type (phosphorous doped) silicon. Resistivity $\sim 1 \mathrm{~cm}$

3. (111) n-type (antimony doped) silicon. Resistivity $\sim 1 \mathrm{~cm}$

4. (111) n-type (phosphorous doped) Lopex or low oxygen silicon. Resistivity $\sim$ Secm.

5. $(100)$ p-type (boron doped) silicon. Resistivity $\sim 1 \Omega \mathrm{cm}$.

Doses of $2-3 \times 10^{14}$ ions $/ \mathrm{cm}^{2}$ using beam currents of $1 \mu \mathrm{amp} / \mathrm{cm}^{2}$ were used. A calculation shows that the implantation takes about half a minute:

$$
\begin{aligned}
\text { dose } & =2 \times 10^{14} \text { ions } / \mathrm{cm}^{2}=3.2 \times 10^{-5} \mathrm{coul} / \mathrm{cm}^{2} \\
\text { current } & =1 \times 10^{-6} \text { coul } / \mathrm{sec} \mathrm{cm}^{2} \\
\text { implant time } & =\text { dose } / \text { current }=3.2 \times 10^{-5} / 10^{-6}=32 \mathrm{sec}
\end{aligned}
$$

Estimates of the temperature rise due to beam heating depend critically on the volume assumed affected by the energy of the beam. If $E$ is the energy deposited by the beam in $32 \mathrm{sec}$ 


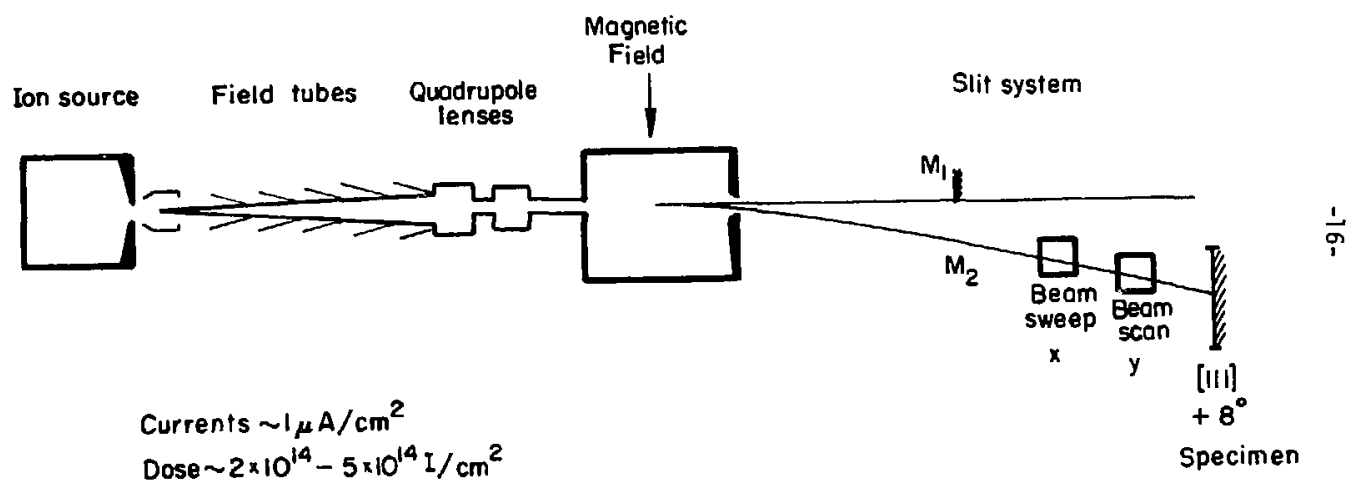

XBL744- 6106

Fig. 2.1. The ion-implantation equipment showing the $i$ in source and the acceierating tubes. The mass analyzing magnet separates ions of one mass e.g., $p_{3}^{3}$. The $x, y$ beam sweeps scari the ion beam across tile specimen. Polished wafers of $\left\langle 117 ;\right.$ silicon, til ted $8^{\circ}$ away from the exact (II) direction in order to minimize Linnelling, were used. 


$$
\begin{aligned}
E=t V I & =(32 \mathrm{secs})\left(10^{5} \mathrm{voits}\right)\left(10^{-6} \mathrm{amps} / \mathrm{cm}^{2}\right) \\
& =3.2 \text { watts } \mathrm{sec} / \mathrm{cm}^{2} \\
& =0.758 \mathrm{cal} / \mathrm{cm}^{2}
\end{aligned}
$$

Assuming that all this heat is retained in a volume of one square centimeter by $2000 \AA$ (range of the ion) the temperature rise $\Delta T$ is related to $E$ by

$$
E=m \cdot C_{p} \cdot \Delta T
$$

where $m$ is the mass $=2.10^{-5} \mathrm{~cm}^{3} \times 2.2 \mathrm{~g} / \mathrm{cc}=4.66 \times 10^{-5} \mathrm{gm}$

$C_{p}$ is the specific heat $=0.162 \mathrm{cal} / \mathrm{g}^{\circ} \mathrm{C}$ for silicon giving

$$
\Delta T=\frac{0.768}{0.755 \times 10^{-5}} \approx 10^{+5^{\circ} \mathrm{C}}
$$

Allowing for an increase in volume affected by over two orders of magnitude a temperature rise of about $500^{\circ} \mathrm{C}$ is still expected.

The importance of effective cooling during implantation is obvious from this calculation. The chips used in this study were clipped on to an aluminum block during implantation and a temperature rise of over $50^{\circ} \mathrm{C}$ was not notfced (Reddi, 1974). Other procedures are possible, such as making an indium base contact to provide good heat conduction (Crowder, 1974). That sample heating is one of the factors which affect whether or not linear defects form is a result of this study (see Chapter $V$ ). 


\subsection{Heat Treatment}

Prior to heat treating the foils they were glued down on a glass slide, implanted side down, with heated wax and discs $2.3 \mathrm{~mm}$ in diameter were cut and dishad in the middle using a ultrasonic cutter. The discs were removed after cutting and dishing by remelting the wax, and cleaned by soaking in 111 trichlorocthylene which dissoives the wax. The discs were then heated in a fore-flushed AGAR induction furnace in a static atmosphere of extra pure helium. In order to check that no impurities were diffusing into the samples another batch was el apsulated in pyrex tubing in a $96 \% \mathrm{He}_{4} \% \mathrm{H}_{2}$ atmosphere. These capsules were heated in a tube furnace. One batch was fast cooled by plunging she capsile in cold water. Subsequent micrascopic analysis failed to revea 1 any significant difference in defect morphology between these three different batches. 


\subsection{Thin Foil Preparation}

After the discs were heat treated they were chemrcaliy thinned in a 3:1 mixture of two solutions $A$ and $B$; $A$ was a mixture of $3: 1$ hydrochloric acid and nitric acid and 8 was a solution of $2.5 \mathrm{~g}$ iodine in $1000 \mathrm{ml}$ of acetic acid. The implanted surface was protected from the solution by sticking the discs, implanted surface down, on the sheets of PTFE. Hot wax was used to stick the specimens. The temperature of melting of the hot wax was $\sim 65^{\circ} \mathrm{C}$. Some annealing is expected to occur at this stage. Thin foils, in the $4500 \AA$ thickness range, were produced by stopping chemical polishing when a perforation was first seen. A light. source was used to aid early detection. ine samples were removed using 111-trichloroethylene and washed in acetone and alcohol before examination. 
CHAPTER III.

OPTIMUM IMAGING CONDITIONS AND IMAGE COMPLEXITIES

3.1. Introduction . . . . . . . . . . . . . 21

3.2. Experimental Results............... 23

3.2.7. $650 \mathrm{kV}$ Optimum Conditions and Complexities . . . . 23

3.2.2. $100 \mathrm{kV}$ Optimum Conditions and Complexities . . . . 27

3.3. Discussion and Conctusions .............. 36 
"Nature is often hidden, sometimes overcome, seldom extinguished." Bacon

\subsection{Introduction}

Defects produced after the annealing of ion bombardment damage are small (in the 200-500 $\AA$ range) and present in high concentrations (over $10^{15}$ defects $/ \mathrm{cm}^{3}$ ). Conventional bright and dark-field images (Fig. 3.la,b) are wide (about $20\left(i_{i r}^{8}\right)$, dominated by strain field effects, and bear no relation to the true shape and size of the defects. Consequently, conventional imaging techniques were of little value in characterizing these defects.

Several nonconventional electron microscopic methods aimed at reducing image width have been announced in the recent years: the weak-beam method (Cockayne et al., 1969), the bright field systematic method (Osieski et al., 1971) and the symmetric weak-beam bright field method (Kelly et al., 1973). It was obvious that such methods could be used to advantage in characterizing the defects in ion implanted silicon.

Since no systematic study exists, it was deemed necessary to determine the best imaging conditions for these defects at $650 \mathrm{kV}$ and at $100 \mathrm{kV}$. An experimental method was used. Thin foils were gradially tilted in the electron microscope from the $(0, g)$ to the $(0,4 g)^{\star}$ diffracting condition and the bright field and weak-beam $( \pm g, n g)$ images were recorded.

\footnotetext{
*The notation used for denoting a certain diffraction condition is as that used by Humphreys et al., 1973: $(\mathrm{g}, \mathrm{ng})$ denotes an inizine using $\mathrm{g}$ with the Ewald sphere passing through $n g .(0, n g)$ is the bright-field image, $(-g, n g)$ is the weak-beam image etc.
} 
Several interesting trends and complications in image behavior were observed.

In order to simulate the observed behavior of the images, computations of image profiles of closely spaced dipoles under systematic conditions have been performed (Chen, 1974). A majority of the trends have beer, explained (Chen et a1., 1974) with the notable exception of the anamolous disappearance of some images in bright field. 


\subsection{Experimental Results}

\subsection{1. $650 \mathrm{kV}$ Optimum Conditions and Complexities}

The images in Fig. 3.2.1 and the traces across the defects show the reduction of image width that exciting combinding good defect visibility with a reasonably narrow image occurs for the $(0,2 \mathrm{gs}+)$ bright field condition, Fig. 3.1.1b and the g,2gs+ weak beam condition for $g=220$ as in Fig. 3.1.2b. Although exciting higher orders of reflection decreases image width, contrast above background drops over $60_{m}^{\infty}$ (Fig. 3.1.1d) so that the defects can hardly be seen. The bright field systematic images require shorter exposures than the weak beam images; the latter yield three times more contrast for the same imaging condition. Experiments showing that che optimum imaging condition for $\mathrm{g}=111$ is the $(0,3 \mathrm{gs}+)$ bright field and the $(9,3 \mathrm{gs}+)$ dark field is shown in Fig. $3.3 e$ and $f$ respectively. These images also show the great sensitivity of the images of small defects to the diffracting condition when several beams are excited. The circled loop is seen, in bright and dark fields, at the exact Bragg conditions $(0,3 \mathrm{~g})$ and $(g, 3 g)$ only: Fig. 3.2c and $d$. Eecause of this anamalous disappearance effect. caution is necessary before concluding that a certain defect is absent when several beams are excited. Another complicating feature in high voltage images may be seen in Fig. 3.2.1c where the line of no contrast of some loops are seen to rotate as $G$ is changed slightly: for instance at loops as well as that adjacent to the rod $R$. Such rotations could lead to incorrect assignments of the Burgers vector specially if specific two-beam models e.g., Belt and Thomas (1965), are used. 

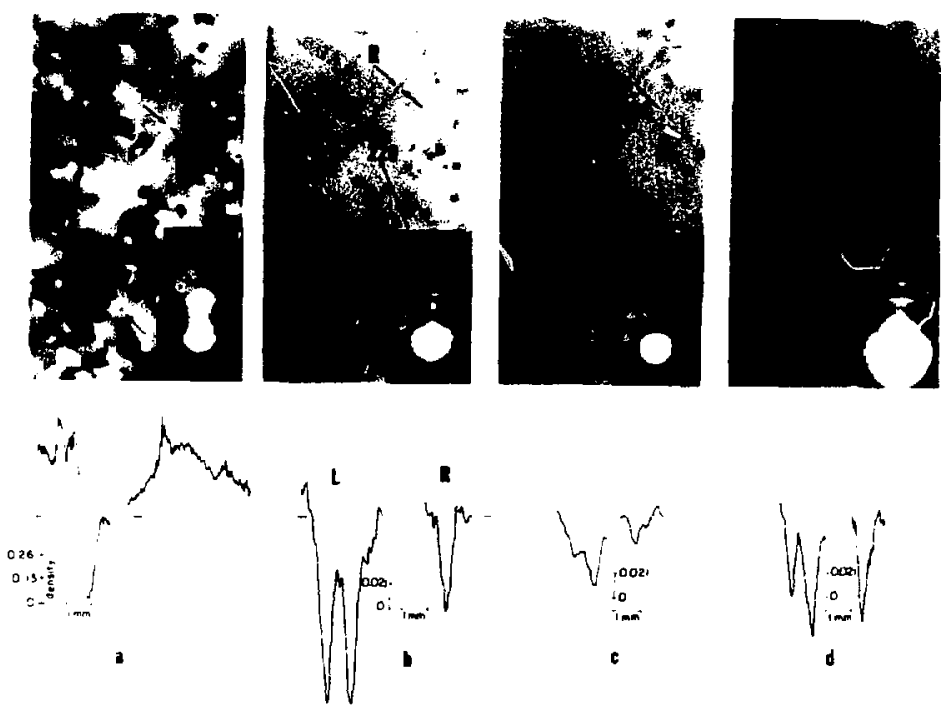

$\times 8 B \quad 7210-5179$

Fig. 3.1.1. Images in bright-field with $9=220$ at $650 \mathrm{kV}$ for the following conditions: a. $(0, g)$, b. 0, ast $), c .(0,2, j)$, d. $(0,2 \mathrm{gs}+)$. Shown below are densitometer trace across the loop $L$ and the "rod-like" defect $R$. The best visibility condition with narrow images was at $d$ : $\left(0,29 s^{+}\right)$. Further tilting resulted in a great loss of visibility. 

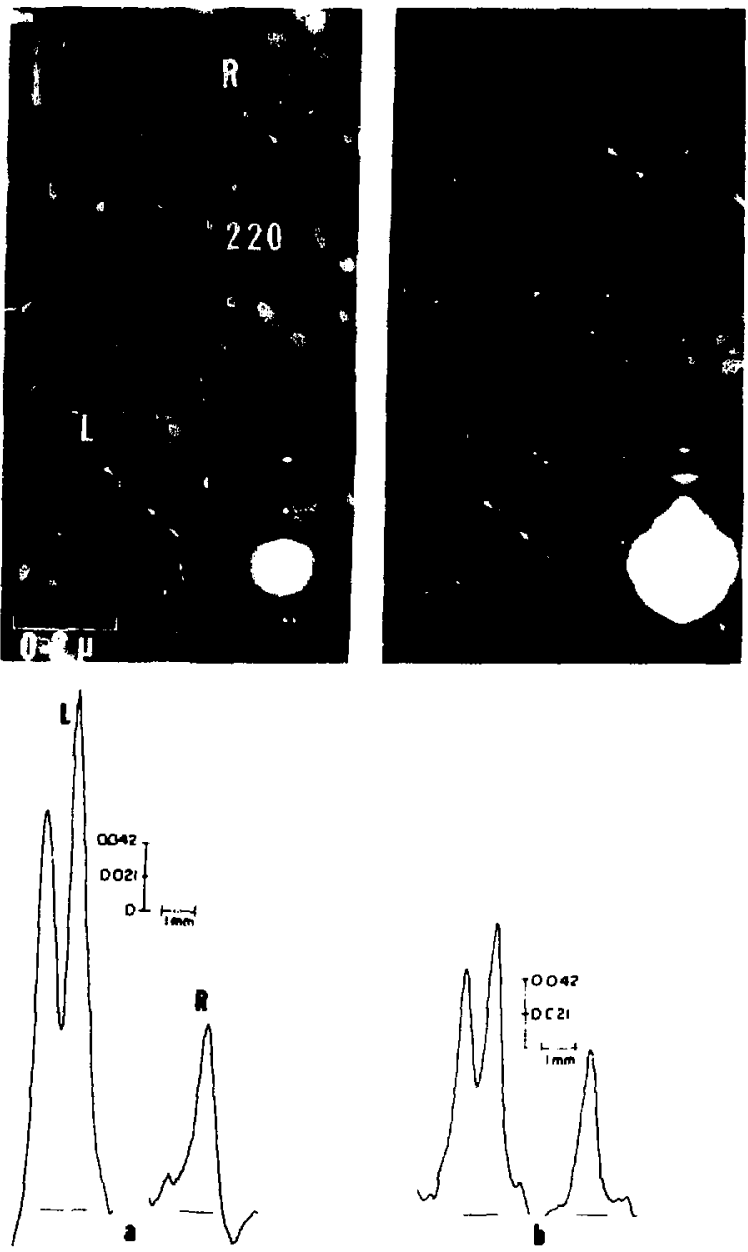

XGB 7210-5178

Fig. 3.1.2. The same area as in Fig. 3.1.1 in dark field under the following conditions: a. $(g, 2 g), b .(0,2 g s+)$, and the traces across $L$ and $R$. This figure illustrates the increase in visibility of darkfield images over bright field images under the same diffrasting conditions (c,f, 3.1.id). These images, however, reçuire much longer exposure (ic sec). 

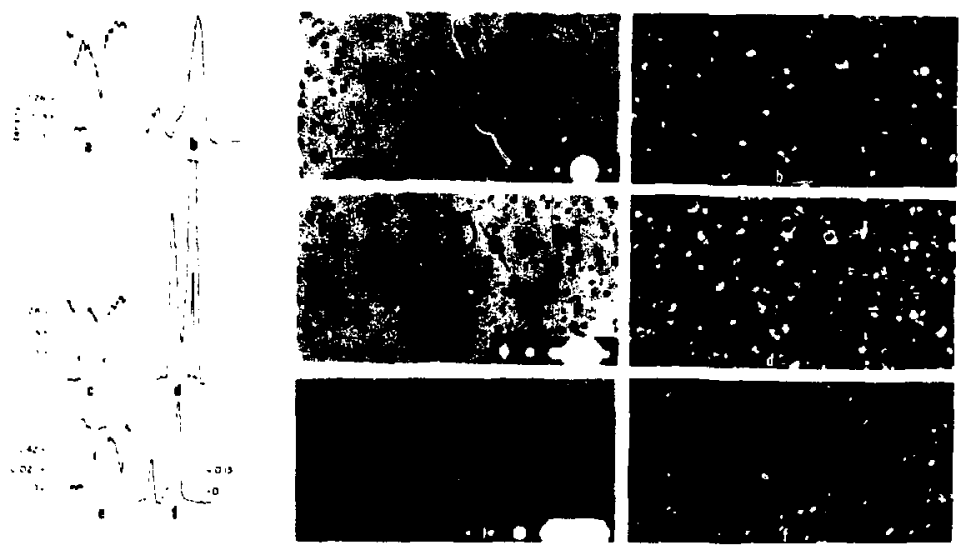

XBB $7210-5180$

Fig. 3.2. Images in bright-and dark-field with $g=11$ at $650 \mathrm{kV}$ for the following conditions: a. $(0,20 s t), D .(g, 2 g s t)$, c. $(0,3 g)$, d. $(g, 3 g)$, e. $(0,3 y s+), f,(g, 3 g s+)$. This figure iliustrates that the visibility of the defects in bright and dark field can change dramatically for small changes in diffracting condition (c.f., a,c or $b, d)$. The circled loop "anomalously" disappears except at the extract Bragg condition ( $c$ and $d$ ).

Computer calculition (Chen et a1., 1975) shows that visibility can also be affected by effective foil thickness and defect size. 


\subsection{2. $100 \mathrm{kV}$ Optimum Condftions and Complexities}

Experiments to determine the optimum conditions at $100 \mathrm{kV}$ are shown in Fig. 3.3. The images and the microdensitimeter traces show that the edges of the loop are test resolved for the $(0,1 \mathrm{gs}+) \mathrm{g}=220$ diffracting condition (Fig. 3.3c). For $g=111$ the $(0,2, g+)$ condition was found optima .

The great enhancement of image detail, the reduction of image width and the increase of accurate information about loop size, shape and habit plares available in weak-beam images is seen in Fig. 3.4. The reason for this is explained in excellent reviews by Cockayne (1973) and is briefly given below. Image widths are to a good approximation of the order of $\xi_{3}^{5} / 3$, where $\xi_{g}^{5}$ is the effective extinction distance, and

$$
\xi_{g}^{s}=\xi_{g}^{0} / \sqrt{1+\omega^{2}}
$$

where $\xi_{\mathrm{g}}^{0}$ is the extinction distance for a certain $g$ and $\omega=$ dimentionless deviation. If two beams $(0, g)$ are excited and the $-g$ beam is imaged, (a) of this beam is larye as it lies outside the Ewald sphere. This makes $\xi_{\mathrm{g}}^{\mathrm{S}}$ small $(-60 \AA)$ and image widths of $-20 \AA$ are routinely obtained by this method. That the habit plane of the loops is $\{111\}$, that the loops are imperfect (Frank) loops, that they are hexagonal and in the $200 \AA$ size range can be deduced from this one image. Such imiges were used for the most part for the characterization of these defects.

A comparison of the accuracy with which the size of a defect amy be estimated by the bright field, symmetric weak-beam bright field (Fig. 3.5b) and weak-beam images (Fig. 3.5c,d) is shown in Table 3.1. Table 3.1 shows the advantages of the reduction of image width obtained 


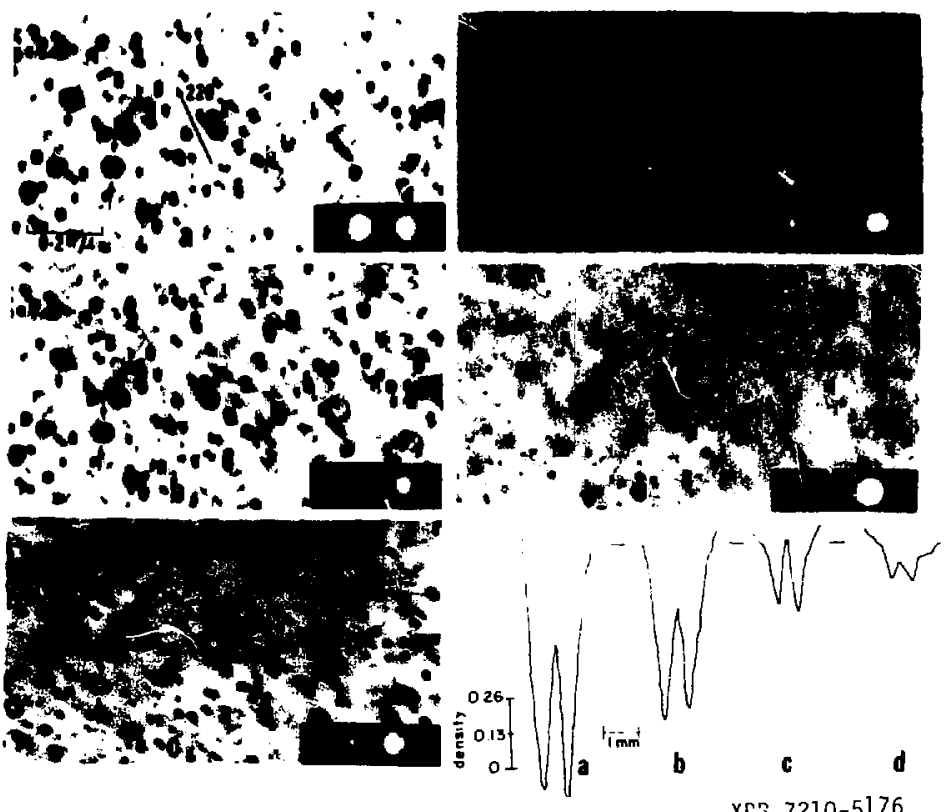

Fig. 3.3. Images in bright field with $g=220$ at $100 \mathrm{kV}$ for the following conditions: a. $(0, g), b .(0, g s t), c .(0, g s+t)$, d. $(0,2 \mathrm{~g})$, e. $(0,2 \mathrm{gs}+)$. Also shown are microdens itometer traces across a loop. The best visibility and narrowest images were obtained for the $(0,1 \mathrm{gs}++)$ condition (c). 


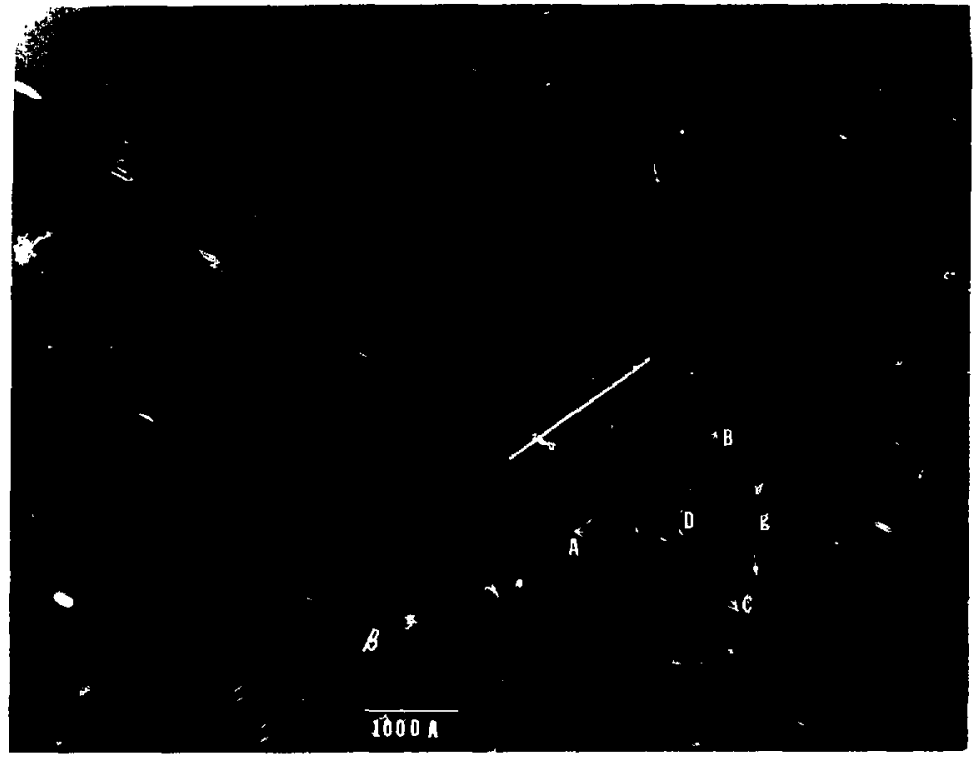

XBB $747-4427 A$

Fig. 3.4. A weak-beam image $(-\mathrm{g}, 3 \mathrm{gs}+)$ at $100 \mathrm{kV}$. This figure illustrates the great enhancement of image detail the weakbeam technique affords. This cne jmage with the Thomson tetrahedron shown can be used to conclude that the habit planes of the loops are $\{111\}$ is marked, that the loops are imperfect (Frank) loops and that they are hexagonal in the 200-300A size range. 
Fig. 3.5. A comparison between images in bright field (a), in the symmetric-weak-beam-bright-field (b) and in weak beam $(g, 3 g) c$, and $(g, 4 g) d$. The SWBBF image requires shorter exposure than the WB images, and produces double images (c) if the loop is faulted or single images if it is perfect (B). The weak-beam images require longer exposures and give reliable dimensions of defects within $\pm 5 \AA$. 

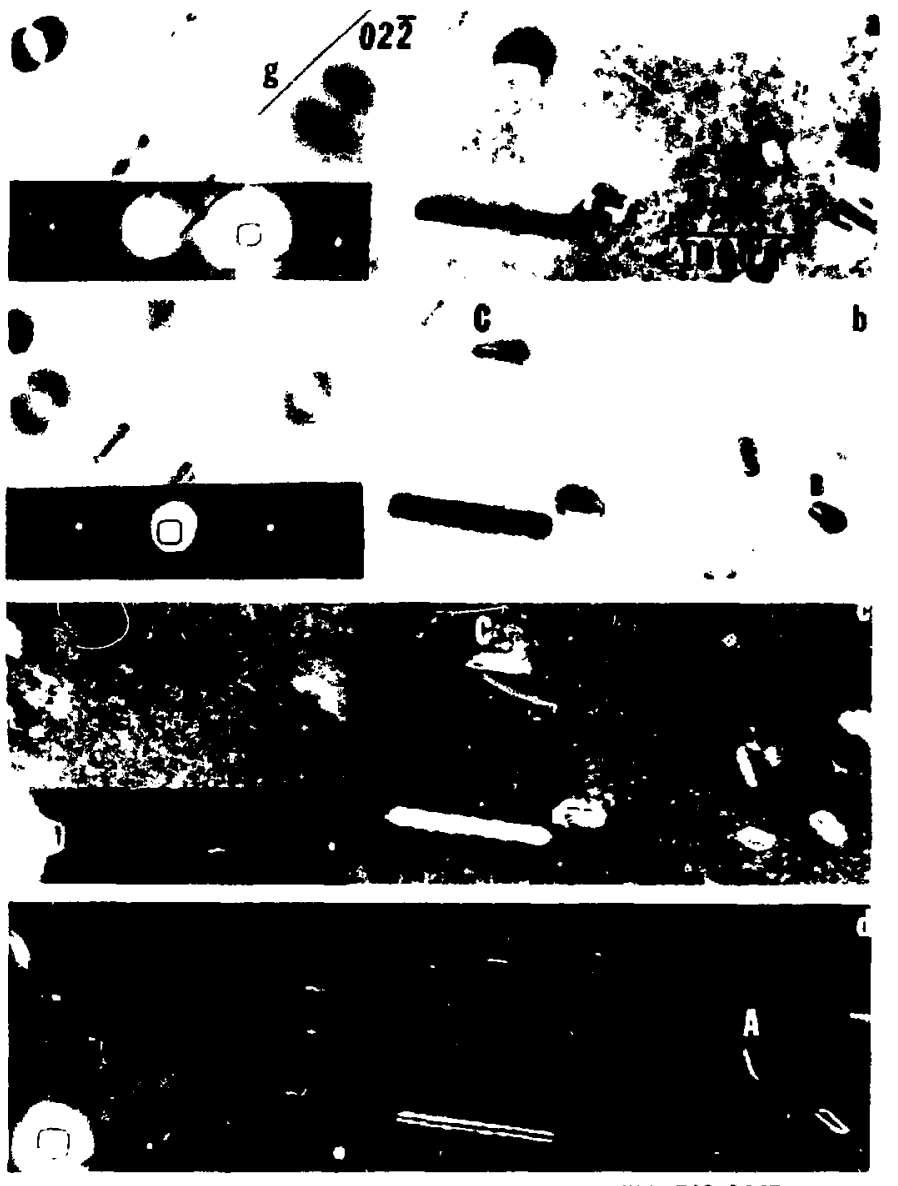

XBB 742-1267

Fig. 3.5 
Table 3.1. Image width and estimated width of defect $B$.

\begin{tabular}{lcccc}
\hline Fig. 3.6 & $\mathrm{a}$ & $\mathrm{b}$ & $\mathrm{z}$ & $\mathrm{d}$ \\
\hline Image Width $\AA$ & 600 & 60 & 55 & 28 \\
\hline $\begin{array}{l}\text { Estimated } \\
\text { Width of Loop } 8 \AA\end{array}$ & undefined & 98 & 110 & 60 \\
\hline
\end{tabular}


by the symmetric-weak beam method (Fig. 3.5b) and weak-beam me..lods (Fig. 3.5c and d) over the conventional bright field image (Fig. 3.5a). In this case this has been used to determine the width of the loop B (Seshan, 1974).

The symmetric weak-beam bright field method requires shorter exposure times $(\sim 15$ secs) than the weak-beam method ( $\sim 60$ secs). It has also proved useful in quickly determining the ratio of faulted to perfect loops (see Chapter IV, p. 63).

Nonconventional images at $100 \mathrm{kV}$ here also found to suffer from image complications arising from the interaction of several beams. This may be seen in Fig. 3.6a,b. Figure 3.6 a shows a bright field and Fig. 3.7a,b $(+g /-g)$ weak-beam of the same area. In the weak-beam îmage (Fiy. 3.7b) just below the hexagonal loop marked $g$ the faint image of a linear defect may be seen; this lies along a [110] direction $\overline{A C}$ according to the Thomson tetrahedson in Fig. $:$ ?a.

The image of this defect is not seen in the bright field ingge (Fig. 3.7a). The absence of the rod in the bright-field image, Fig. 3.7a, and its presence in the weak-beam image (Fig. 3.7b) confirms that $100 \mathrm{kV}$ bright field images are liable to the anamalous disappearance effect. The computer simulations (Chen et al., 1974) show this could arise from defect position in the foil defect width, foil thickness and diffraction conditions. 
Fig. 3.6. Shows a bright-fie?d and weak-beam image of the same area. The figure, lows that the visibility of the defects, even in bright field, is ver: sensitive to the diffracting condition. For example, the linear defect at $M$, visible in the $W-B$ image ha; "anomalously" disappeared in the $\bar{B}-\mathrm{F}$ image. The figure also shows the four sets of Frank loops inarked with respect. to the Thomson tetrahedron. 

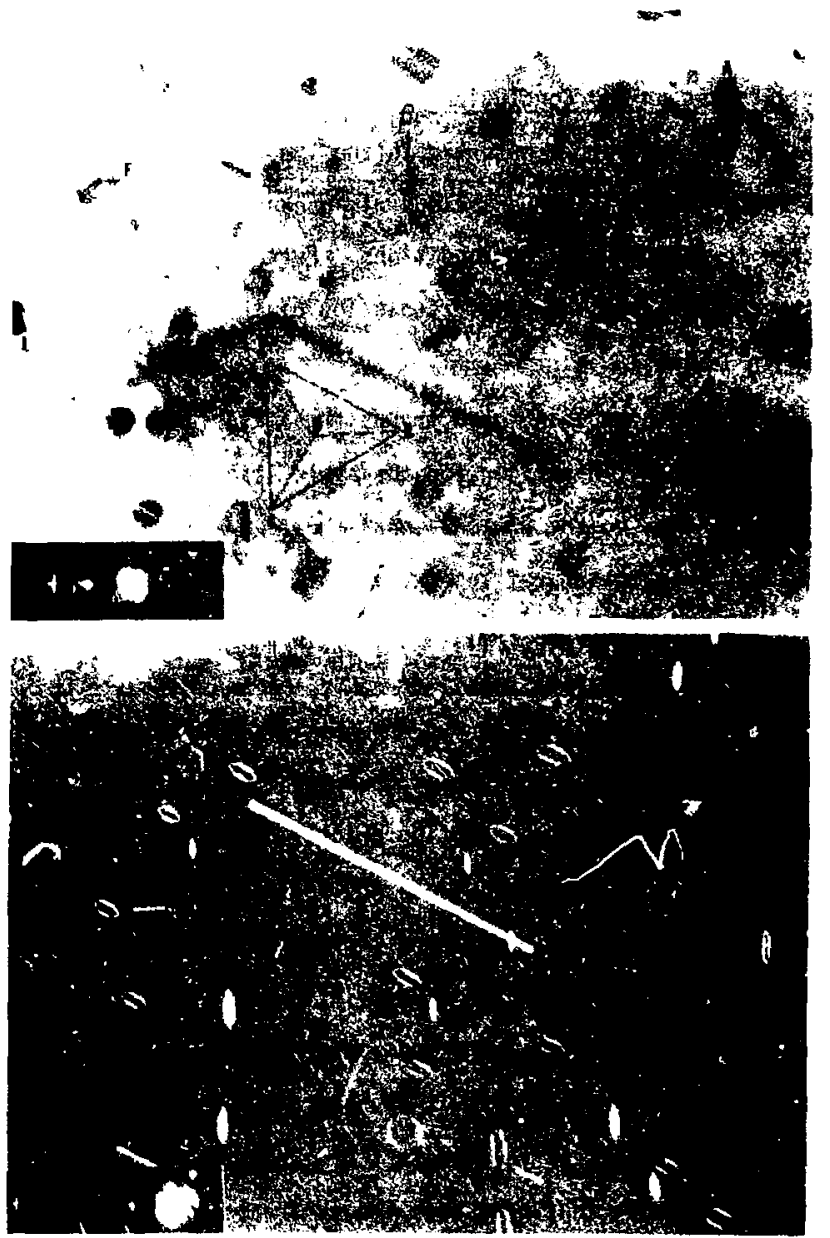

$\checkmark 1 \therefore .1425$ 


\subsection{Discussion and Conclusions}

One common feature observed in the $100 \mathrm{kV}$ and $650 \mathrm{kV}$ bright and dark fieid images is the anamalous disappearance effects for small changes in the diffracting conditions. Further, a definite trend in the optimum conditions for resolution of the images were seen as shown in Table 3.2 .

In order to explain these trends the images of closely spaced dipoles $(60-500 \AA)$ in silicon for the systematic cases with up to seven beams excited using the Howie-Basnski (Howie and Basinski, 1968) were computed. From these profiles the visibility defined as:

$$
\text { visibility }=\left(I_{\max }-I_{\min } / I_{\max }+I_{\min }\right) \text {, }
$$

was detemined (Chen, Seshan and Thomas, 1974). This quantity was found to drop from 0.8 to 0.1 for changes in sg the deviation parameter of $2 \%$. Such a variation exactly Juplicates the behavior of images such as that in Fig. 3.3 and 3.7.

The visibility was also found to vary with size and depth of the defect in the fcil and quite markedly with foil thickness. Stereomicroscopic data show that the rods seen in Fig. 3.8 are distributed over a depth range of $2000 \AA$. It is, therefore, quite likely that the disappearance effect is related to the defect size and depth in the foil. It is knowi that weak beam images are sensitive to the depth of the defect in the foil (Perrin and Eyre, 1973). This study shows that bright field images of small defects in silicon suffer the same effect at 100 and $650 \mathrm{kV}$. 
Optimum imaging conditions--experimental and theoretical.

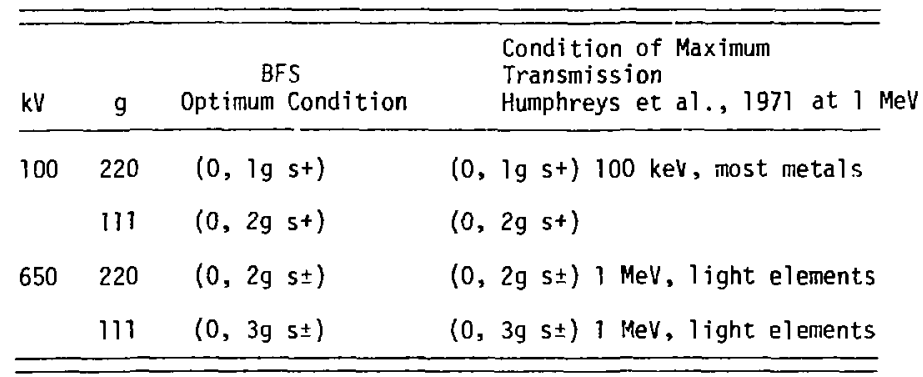


As may be seen in Table 3.2, there seems to be a relation between experimentally determined optimum conditions and the conditions for goad transmission as determined by Humphreys, Thollas, Lally and Fisher, 1971. For instance, they determine from Bloch wa'.? intensity calculations that the conditions for best transmission for light elements in bright field with $g=220$ is just positive or negative of the second order Bragg position; this is also the best imaging condition in Fig. They find that conditions of good transmission at $100 \mathrm{kV}$ are poor transmission conditions at $1 \mathrm{MeV}$; in the study of images it is seen that the $(0,1 \mathrm{gs}+)$ cond.tion which is the optimum condition at $100 \mathrm{keV}$, Fig. $3.4 \mathrm{c}$, is a poor imaging condition at $65 \mathrm{c}$ l. V, Fig. 3.2.1b. Although these studies suggest a connection between electron penetration and image contrast, the detailed mechanism has not beeil worked out.

Non conventioncil images at $100 \mathrm{keV}$ were found to have the required resolution to characterize these defects and were used for the most part. The only limitation was that thin areas of the foil $(2-3000 \AA)$ had to be used. This may yield misleading information about defect depth distributions as the defects are expected at depths up to $4000 \AA$ in the foil. Therefore, for stereo macroscopic work relating to the depth distribution of the defects high voltage images, where thicker foil sections $(8000-10,000 \AA)$ could be imaged, were used. 
CHAPTER IV.

CHARACTERIZATION OF THE DEFECTS

4.1. Introduction . . . . . . . . . . . 40 40

4.2. Characterization .............. 42

4.2.1. Determination of Habit Planes ........ 42

4.2.2. Determination of Defect Type ......... 49

4.2.3. Depth Distribution and Contrast Effeci.s . . . . 57

4.3. Defect Morphology-Silicon Prehistory . . . . . . . . 62

4.4. On the Presence of Linear Defects ... . . . . . . 44

4.5. Discussion and Conclusions............ 72 
"He's got 'em on the list, he's got them on the list

And they'll none of them be missed, none of them be missed." Mikado

\subsection{Introduction}

An unambiguous characterization of the defects forned upon annealing ion-damaged silicon is necessary before a model for their formation is proposed. Contradictory descriptions of their nature have been advanced owing probably to their small size, high densities and complex image behavior (Chapter II). The loops formed upon annealing were i irst described as perfect with burgers vectors of the type a/2[110]; their habit planes were, however, not exactly determined (Davidson and Booker, 1970; Bicknell and Allen, 1970; Tamura et a1., 1972; Wu et al., 1974). Most of these investigators reported interstitial loops except Chadderton and Eisen (1970) and Bicknell (1973) who reported vacancy loops. More recently, using weak beam techniques a majority of the loops have been reported as interstitial and imperfect i.e., interstitial Frank loops with a/3[111] displacement (Jenkins et al., 1973).

The occurrence of linear defects in $\mathrm{P}^{+}$implants constitutes another perplexing problem. Such defects are observed in great abundance in $\mathrm{B}^{+}$implants into $\mathrm{n}-\mathrm{silicon}$. However, in $\mathrm{P}^{+}$implants into $\mathrm{p}-\mathrm{silicon}$ they were first reported to be absent (Bicknell and Allen, 1970). They associated with this the absence of negative annealing in $\mathrm{P}^{+}$implants. Linear defects were present in the room temperature $\mathrm{P}^{+}$and $\mathrm{Si}^{+}$implants used in this study (Seshan and Washburn, 1972), and were al so reported in high temperature implants by Tamura et a1. (1972). More recently shorter linear defects than those found in $\mathrm{B}^{+}$implants have been reported by Madden (1973) in $\mathrm{P}^{+}$implanted p-silicon. 
In this study, $210^{14} 100 \mathrm{keV}$ ions per $\mathrm{cm}^{2}$ were implanted as below:

a. $\mathrm{P}^{+}$ions in $\mathrm{p}$ (boron doped) 111,100 silicon $0.25-8 \Omega \mathrm{cm}$

b. $\mathbf{p}^{+}$ions in $\mathrm{n}$ (phosphorous doped) 111 silicon $1 \Omega \mathrm{cm}$

c. $\mathrm{P}^{+}$ions in $\mathrm{n}$ (phosphorous doped) "lopex" silicon $1 \Omega \mathrm{cm}$

d. $\mathrm{P}^{+}$ions in $\mathrm{n}$ (antimony doped) 111 silicon; $1 \Omega \mathrm{cm}$

e. $\mathrm{Si}^{+}$ions in $\mathrm{p}$ (boron doped) $111 \mathrm{silicon;} 1 \mathrm{sm}$

It is shown in Chapter 1 , part 1.2.1, that the dose used was below that required for the onset of a completely amorphous layer and that a high density of isolated amorphous or disordered zones are expected.

In this chapter the determination of the habit planes of the defects are described by large angle tilting and by the calculation and comparison of some inclination dependent contrast features in Section 4.2.1. Whether the defects on the inclined planes and those in the foil plane are interstitial or vacancy is detemined in Section 4.2.2. In Section 4.2.3 the depth distribution of the defects found by stereonicrascopy is descrived. Some unusuai contrast features exhibited by the loops are also discussed. In Section 4.3 the effect of silicon prehistory on defect morphology is described. In Section 4.4 some experimental observations on the 1 inear defects are presented. 


\subsection{Characterization}

\subsubsection{Determination of Defect Habit Planes}

The habit planes of large loops an simply be determined by tilting the foil to orientations where the defects appear edge on. The images of small defects, however, are so dominated by their strain fields that images under conventional contrast conditions are insensitive to changes in orientation; see Fig. 4.4 for example.

In weak-beam images changes of loop orientation are more readily visible (Fig. 4.1). A special wedge was constructed in order to effect this tilt in the Philips EM 301 high resolution instrument. In Fig. 4.1(a) a 111 foil is tilted to the 112 pole where one of the loop variants, $B$, appears edge on. In Fig. $4.1(b)$ a similar foil is tilted to the [233] pole. Consistent with the view that the defects lie on $\{111\}$ planes, the varient appears flatter. In Fig. 4.1 the tetrahedron of \{111\} planes is shown with the Thomson notation.

If the displacement vector of the defects is a lattice vector their images should show displacement fringe contrast as seen in Fig. 4.2. This together with their symmetrical hexagonal shape is positive evidence that the loops are Frank loops, and inclose a stacking fault. Their hexagonal shape is indicative of the fact that they are in growth stages where jog nucleation is the critical step (FriedeT, 1969) and that the Frank dislocation inclosing the stacking fault is split into a stair rod and a Shockley partial dislocation (Hirth and Lothe, 1973).

The fringe spacing $p$ is related to the effective extinction distance $\varepsilon_{w}^{g}$ and the inclination $\theta$ of the defect to the foil surface by 

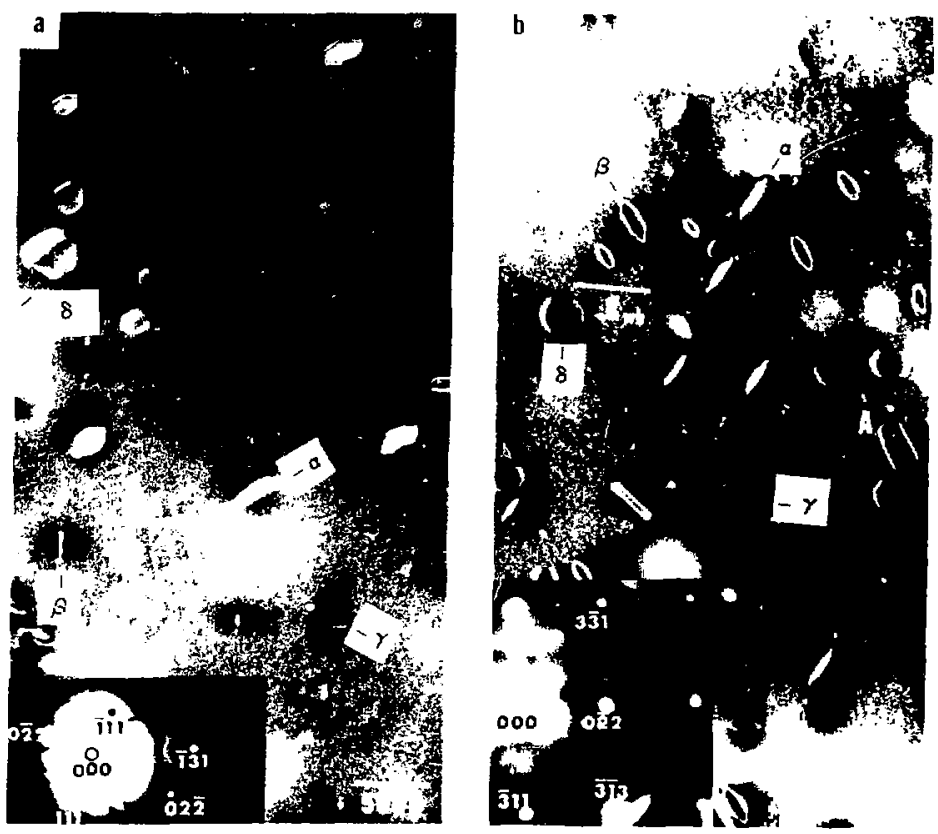

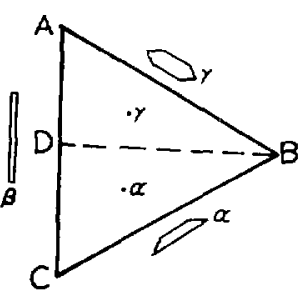

[2II]

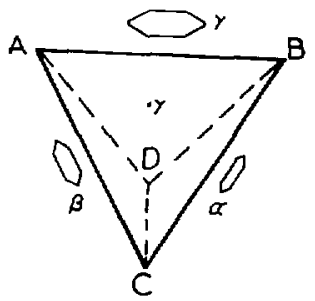

[233]

XBB $745-3335$

Fig. 4.1. (a) Weak-beam image of 211 and (b) at 233. The Thompson tetrahedron corresponding to these poles is showr. At the 271 dole the 3 varient of the Frank loop should appear edge-on as is the case (a). At the 233 pole the y varient should appear slightly larger in projection than is and $\mathrm{E}$ as is also the case. These images were used to conclude that the loops form a family of Frank loop on the four 1111 t planes. The varient marked 5 lies in the foil plane (111) and always appears by residual contrast. 


$$
p=\xi_{g}^{W} \operatorname{Cot} \theta \quad \text { (see Fig. 4.3(a) and Table } 4.1 \text {, }
$$

$\xi_{g}^{W}$ is calculated from the formula

$$
\xi_{g}^{W}=\xi_{g}^{0} / \frac{\xi_{g}^{0}}{\sqrt{1+w^{2}}} \quad \text { column } 5
$$

where $\xi_{g}^{0}$ silicon, $g=220$, is $760 \AA$

$$
\begin{aligned}
w= & s \xi_{g}^{0} \quad \text { column } 4 \\
s= & \text { deviation parameter which is calculated as } \\
& \text { shown in Fig. } 4.3 \text { and listed in column } 3
\end{aligned}
$$

In Table 4.1 the measured fringe spacings are within $\pm 10 \AA$ of those calculated assuming that $\theta=70^{\circ}$ i.e., that the loops lie on $\{111\}$ planes. This is further justification that the loops lie on an inclined $\{111\}$ plane.

The edges of the hexagonal defects 1 ie along $(110)$ and projected (110) directions (Fig. 4.2, Fig. 4.6(b)). Since only the \{111\} planes contain three coplanar (110) directions, this is also evidence that they lie on 111 planes. The sides of the loops lying on the foil $\delta$ plane (Fig. 4.6(b)) are equal, whereas, those on inclined planes have the inclined sides fore shortened. The ratio of the length of these sides reflect the angle through which the loops have been rotated. This angle was calculated for several loops and angles around $68^{\circ}$ were found. This within $10 \%$ of the true $70^{\circ}$ tilt assuming the loops lie on $\{111\}$. 
Table 4.1. Fringe spacing as measured on the electron micrograph are shown in Column 7 . These agree within experimenta? error $( \pm 10 \AA)$ with calculated values assuming that the loops 7 ie on an inclined $\{111\}$ plane shown in column 6 .

\begin{tabular}{ccccccc}
\hline 1 & 2 & 3 & 4 & 5 & 6 & 7 \\
\hline $\begin{array}{l}\text { Weak-Beam } \\
\text { Reflecting } \\
\text { Condition }\end{array}$ & Fig. & $(\mathrm{sg}) \AA^{-1}$ & $\omega$ & $\AA$ & $\begin{array}{l}\text { Calculated } \\
\text { Spacing } \AA\end{array}$ & $\begin{array}{l}\text { Measured } \\
\text { Spacing } \AA\end{array}$ \\
\hline$(\mathrm{g}, 2 \mathrm{~g})$ & $4.1 \mathrm{a}$ & $5.05 \times 10^{-13}$ & 3.83 & 190 & 69 & 70.5 \\
$(\mathrm{~g}, 3 \mathrm{~g})$ & $4.1 \mathrm{c}$ & $1.14 \times 10^{-3}$ & 8.65 & 87 & 32 & 35 \\
$(\mathrm{~g}, 4 \mathrm{~g})$ & $4.1 \mathrm{~d}$ & $2.02 \times 10^{-2}$ & 15.3 & 49 & 18 & 20 \\
\hline
\end{tabular}


Fig. 4.2. a. $(g, 2 g)$, b. $(g, 2 g s+), c .(g, 3 g), d,(g, 3 g s+)$, e,f. $(g, 4 g)$. A series of weak-beam images $(g, n g)$ where by tilting $n$ is changed as above. Going from a to $e$ the effective extinction distance decreases and the number of displacement fringes within the loops increases (c.f. loop $A$ iil Fig. 4.2a and 4.2e). The spacing between the fringes was used to calculate the inclination of the loop habit planes and it was confirmed that they were $\{111\}$. The edges of the defects (e.g., A) lie along (110) directions and is additional evidence that the loop habit plane is \{111\}. 


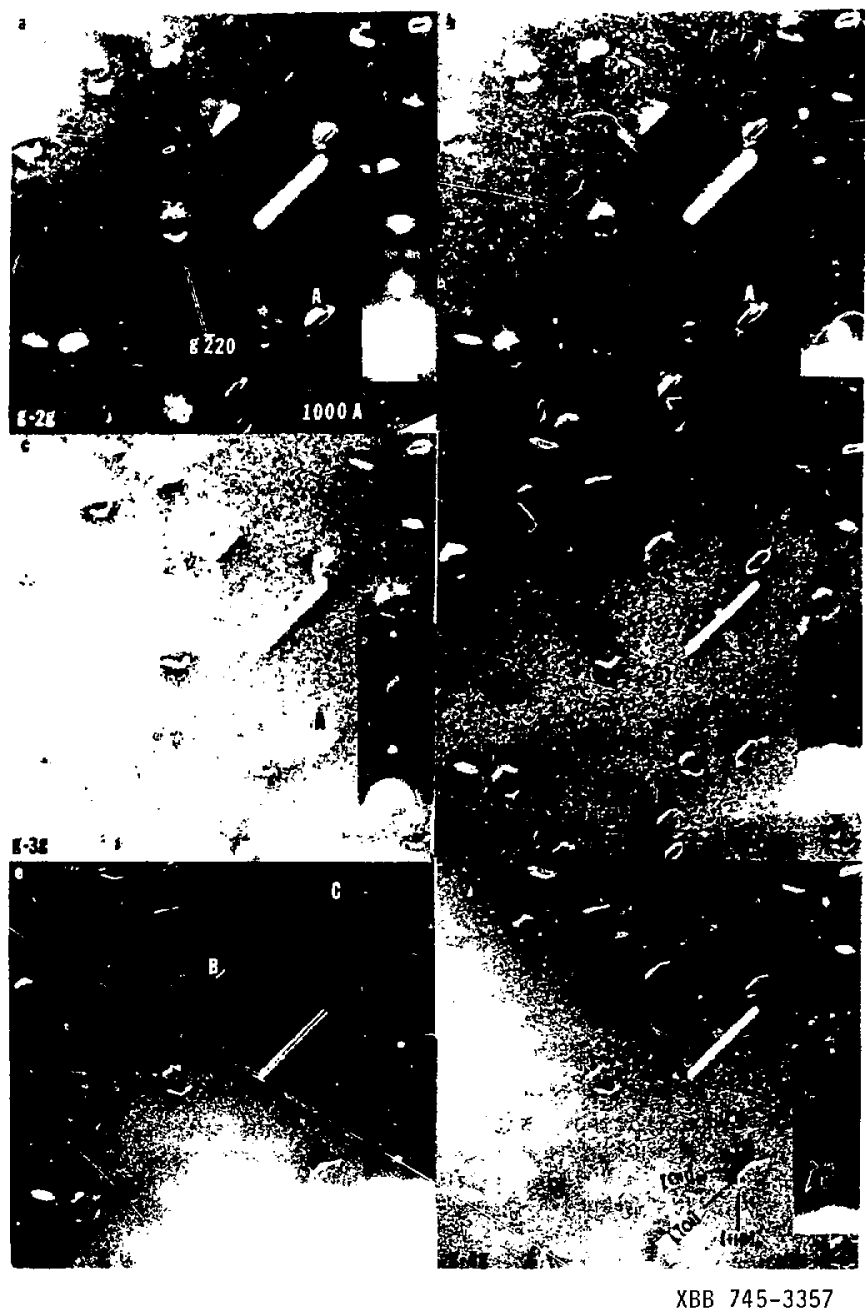

Fig. 4.2 


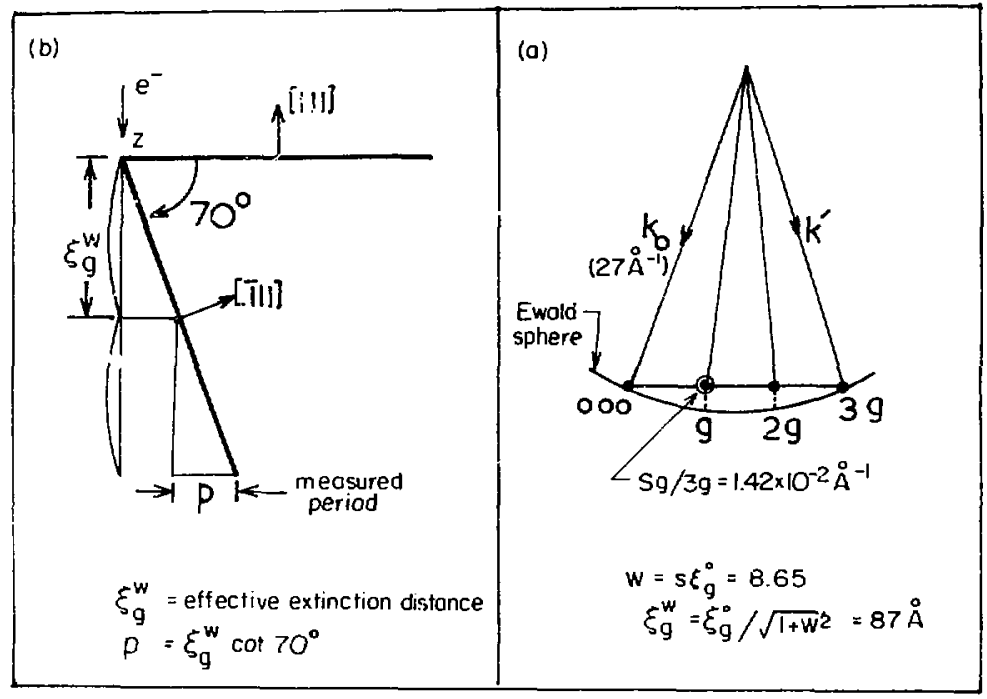

XBL $747-6675$

Fig. 4.3. (a) Shows the reflection condition satisfied for the $(g, 3 g)$ condition corresponding to Fig. $4.2 \mathrm{c}$. The calculatinn of the deviation "s" for the reflection $g$, of $w$ the dimensionless derivation and the effective extinction distance $\xi_{W}^{g}$ is illustrat?d. (b) Illustration of how the value of the effective extinction $\mathrm{g} g$ is used to calculate the fringe spacing. Notice that the fringe spacing depends on the angle the defect habit plane makes with the foil plane. This angle is $70^{\circ}$ if the defects are assumed to be on \{117\} planes. 
From the above it is concluded that the defect habit planes for the great majority of loops on the p-type foils examined were $\{111\}$ and that they were Frank loops. In addition, there were a few unfaulted perfect loops as at A in Fig. 4.1 which show very dark interiors (see Section 4.2.3). Linear defects in densities of about $10^{15} / \mathrm{cm}^{3}$ were also found. Loop densities are of the order of $10^{15}-10^{14} / \mathrm{cm}^{3}$ (Davidson, 1971; Madden, 1973).

\subsubsection{Determination of Defect Type}

Defects lying on the incliried 111 planes were first analyzed; they are easily imaged with reflections in the 111 zone. The loops in the foil plane were analyzed at the (112) pole using $g=11 \overline{1}$.

The stereo pair in Fig. 4.4 is used to find the loop type. These images demonstrate that it was impossible to determine loop habit from conventional images. That the habit is $\{111\}$ was determined using weak beam images and described previously (Section 4.2.1). Accordingly in Fig. 4.4, the loops marked $B$ showing outside contrast are expected to be on the 111- $\beta$ plane and those marked $\gamma$ and showing inside contrast on the $111-y$ plane. The analys is of the strain coritrast is shown in Fig. 4.5. Using the formal FSRH analysis (Hirsh et a1., 1969) the $B$ varient shows outside contrast requiring that $\left(g \cdot R_{B}\right) s<0$. Since $s$ is positive and $g$ is fixed as shown, $R_{\beta}$ must be as drawn in $\mathrm{Fig}$. 4.5c, requiring that the loops are interstitial. The same is true of the $y$ varient. The same result is found $i i$ the rotation of the $p l a n e s$ around the defect is examine $(\mathrm{Fig} .4 .5 \mathrm{C}$ ). These analyses confirm that the loops in the inclined planes are interstitial frank loops.

Loops in the foil plane ( $\delta$ loops) are analyzed in Fig. 4.6. In Fig. 4.6a and $\delta$ loops appear by residual contrast. Using the specially 


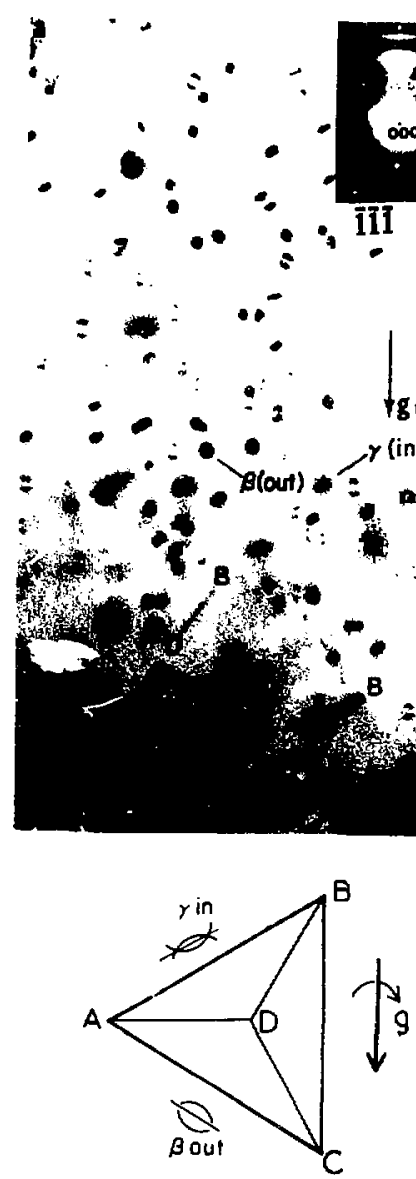

[iाi]
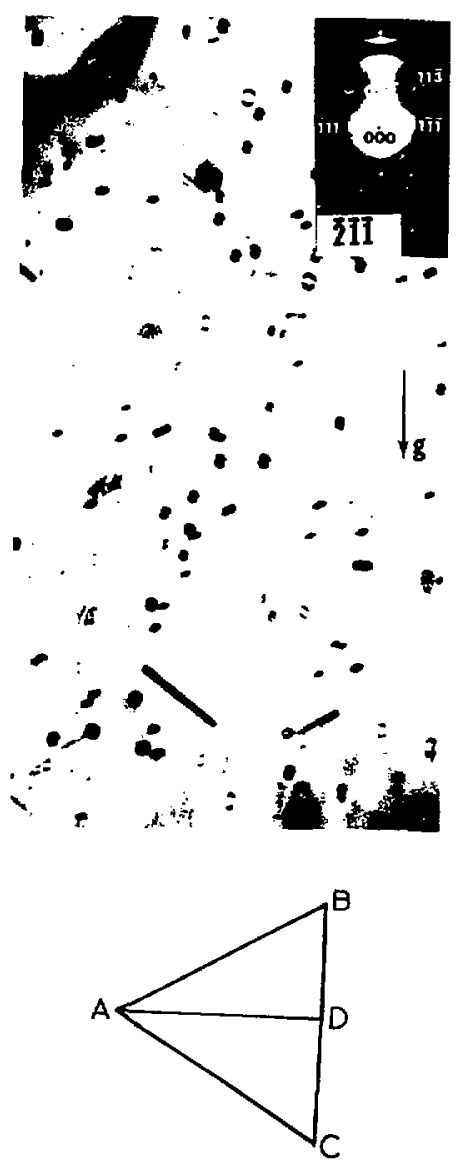

[2]і]]

X8B 745-3334

Fig. 4.4. A bright field stereo-pair where (a) is near 111 and (b) is near 211. Hotice thiat the $B$ varient shows outside $\left(g, R_{B} \cdot 0\right)$ and the $r$ varient inside $\left(g, R_{B} \cdot 0\right)$ contrast. " $S$ " the deviation is positive for both images shown in the diffraction pattern. 


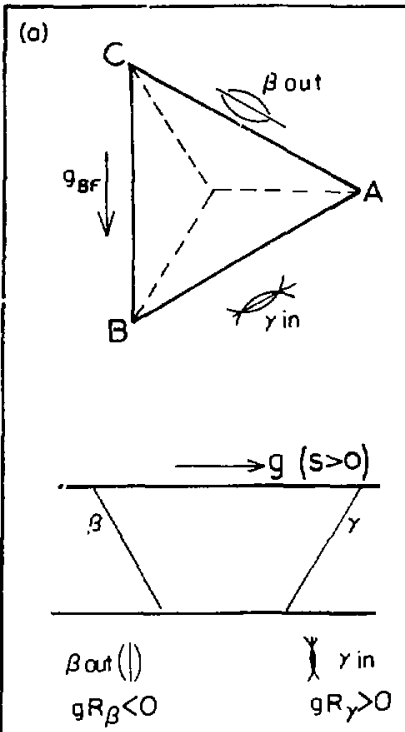

Situation as found in Fig. 20

(c)

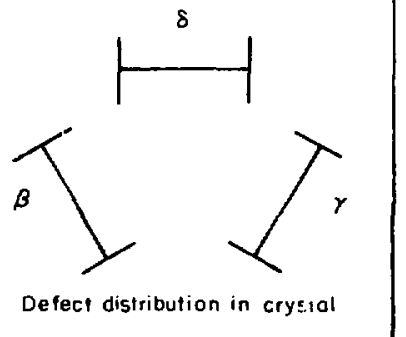

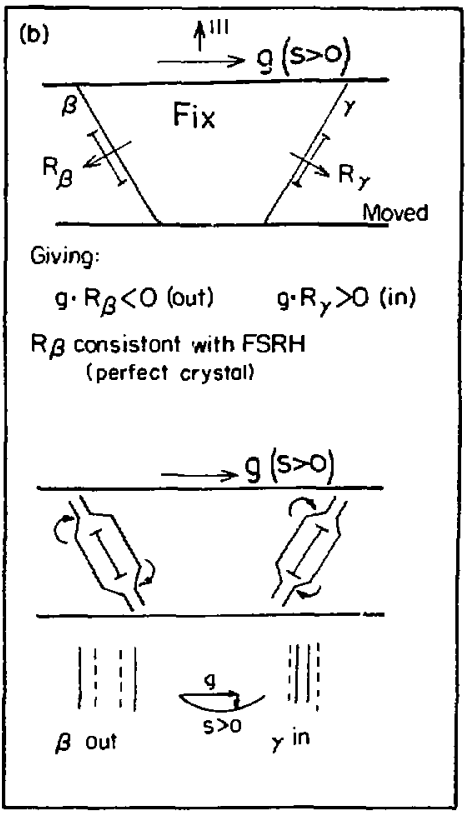

XBL $745-6241$
Fig. 4.5. Analysis of the loop type in Fig. 4.4. (a) Shows the inclinations of the $B$ and $\gamma$ planes in top and side view with the information obtained from Fig. 4.4.

(b) Shows the analysis in terms of the FSRH convention. If the top of the crystal is fixed, $R_{\beta}$, and $R_{y}$ must be as shown. The analysis is repeated taking the bending of the planes into account. The result is that the loops are interstitial. (c) Shows tise distribution of interstitia? defects on the four $\{111\}$ planes. 
constructed wedge, the foil was tilted to the [112] pole where the $\delta$ loops appear as grey regular hexagonal discs. They appear in strong contrast in Fig. $4.6 \mathrm{~b}$ and weak contrast in Fig. 4.6c. This special feature is discussed in detail in the next section. At $C, D$ and $E$ some perfect loops showing very dark inside contrast appear.

The determination of loop type is shown in Fig. 4.7. The inside contrast in Fig. $4.4 b$ requires that $(g \cdot R \delta) s>0$. Since $\hat{g}$ is fixed and $s$ is positive as shown, $R \delta$ must be as shown in Fig. 4.7e; consequently the loops are interstitial. Analysis of the rotation of the planes yields the same result; it was concluded that the loops on the foil plane were also interstitial.

This conclusion is strongly corroborated by the interesting reaction between a loop on the [111] foil plane and one on an inclined (111) plane at $E$. Since the two stacking faults meet at $120^{\circ}$ and the other two Frank dislocations appear to have attracted one another the two loops participating in the reaction are of the smae type viz interstitial.

One researcher foulu vacancy loops in the foil plane upon annealing $\mathrm{P}^{+}$ion damage. This would imply that stress plays a major role $i, y$ the type of loop nucleated on a given habit plane. It should also lead to a preferential distribution of a given set of loops within a depth range where the internal stress favors their nucleation. No evidence for this effect was observed in the presert experiments.

Stereo measurements which indicate that there is no depth segregation of loops by habit plane or type, are presented in the following section. The loops in the foil plane are well distributed among those 


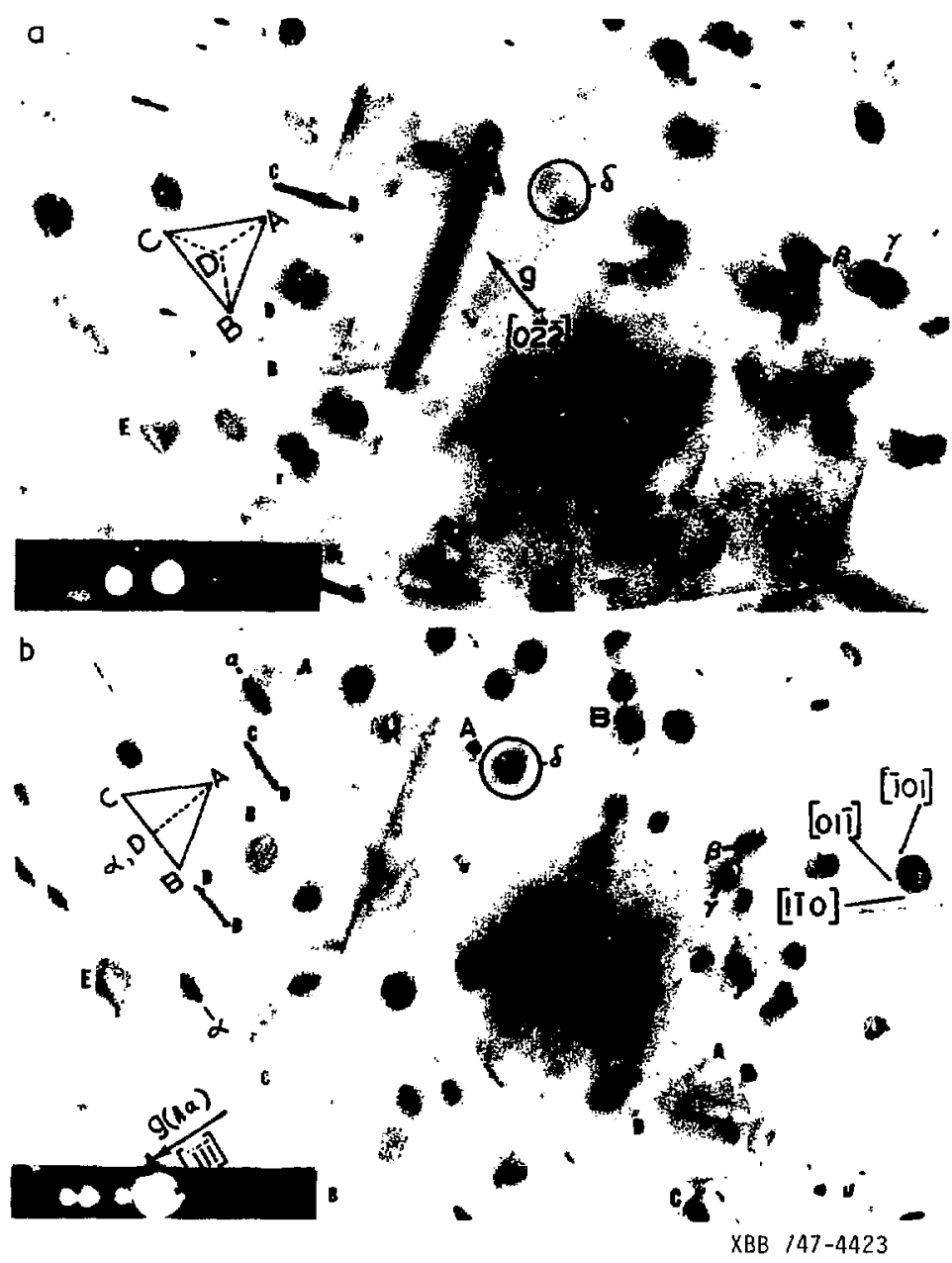

Fig. 4.6. (a) Shows a bright-field image at the 111 pole where the loops in the foil plane $(\delta)$ are in residual contrast; the other varients present $(B, Y)$ are indicated. (b) Shows the same area at the 211 pole using $\mathrm{g}=11 \mathrm{~T}$. The loops in tre foil plane s are visible and show strong inside contrast. They are hexagonal with sides along (110) directions. Linear defects along the various $(110)$ directions are marked. Loops B, C and D are perfect loops and show very dark inside contrast. 

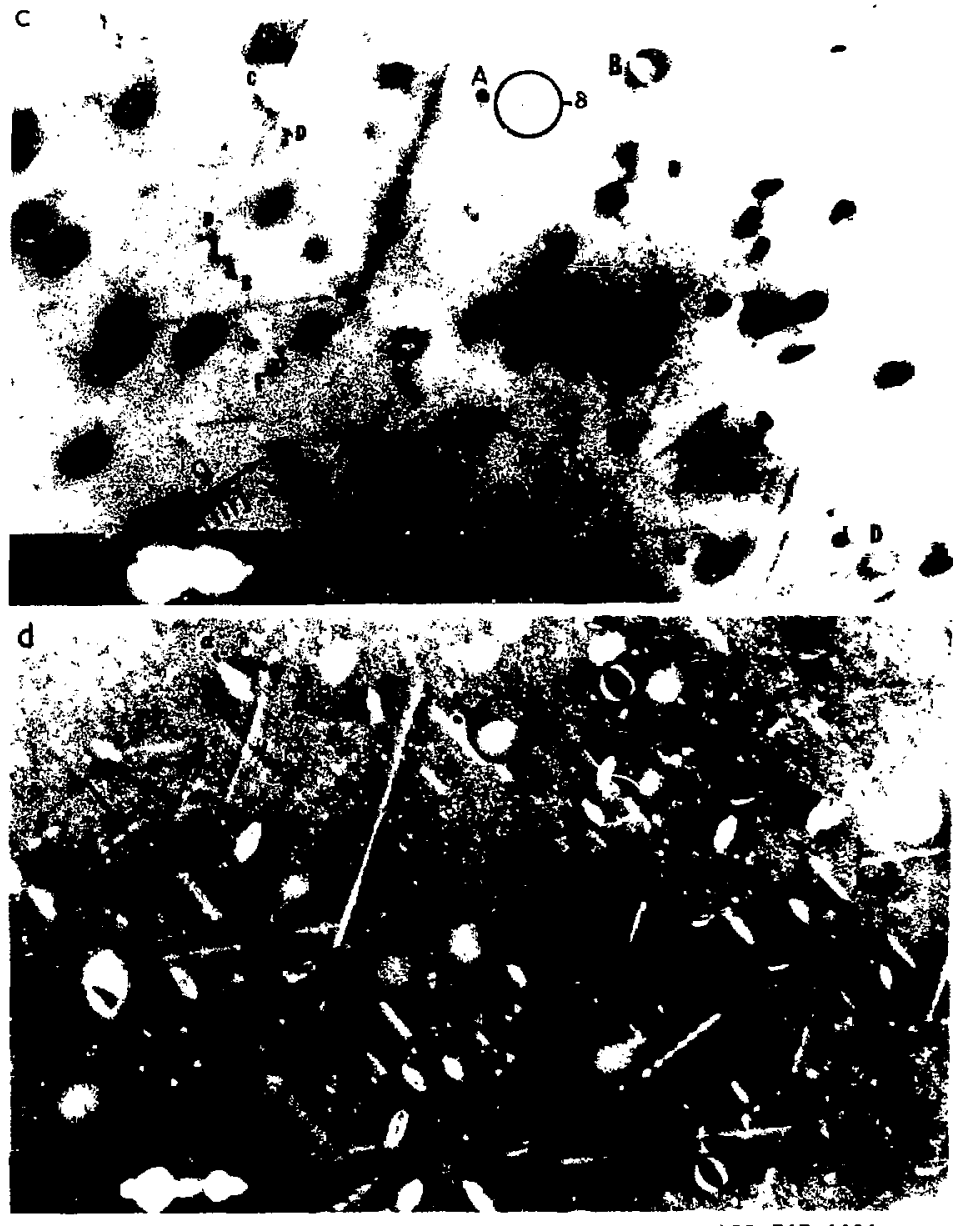

XBB 747-4424

Fig. 4.6. (c) The same area in $g=\overline{1} 11$. The $\delta$ loops now show very weak outside contrast. It was checked that this effect depends only on the sign of $(g \cdot s) \mathrm{s}$. (d) The same area in $(-g, 2 g s+)$ weak-beam. The various sets of defects are marked accorcing to the Thomson tetrahedron. The perfect loops $A, B$ and $C$ show very dark interiors. At $E$ is a reaction between a loop on the $\delta$ plane and one on the inclined o plane. 
Fig. 4.7. Analysis of loops in the foil plane d. (a) Shows the crystal in top view. The poles shown are projections below the crystal. (b) The same crystal tilted to the $2 T T$ pole (as in Fig. 4.6b). The vectors $\hat{n}$, the foil normal, $\hat{g}$ and the sign of s pertaining to Fig. $4.6 \mathrm{~b}$ are shown. (c) The $\delta$ loops in Fig. $4.6 \mathrm{~b}$ show inside contrast requiring that $g R \delta>0$. Therefore, the direction of $R \delta$ should be as shown in Fig. (c). The loops in the foil plane are therefore interstitial. (d) The analysis taking the rotation of the planes into account giving the result that the (d) loops are interstitial. 

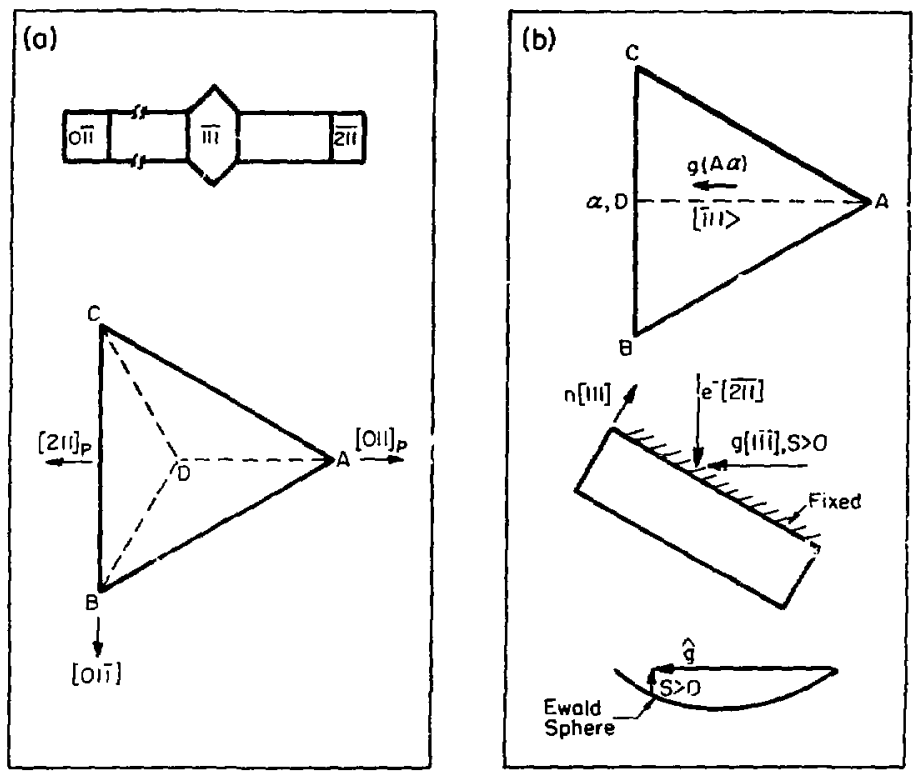

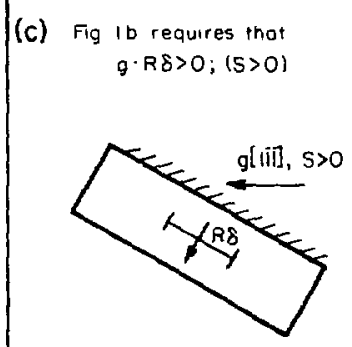

Interstitial Loops Give g. R8>0 (S>0)

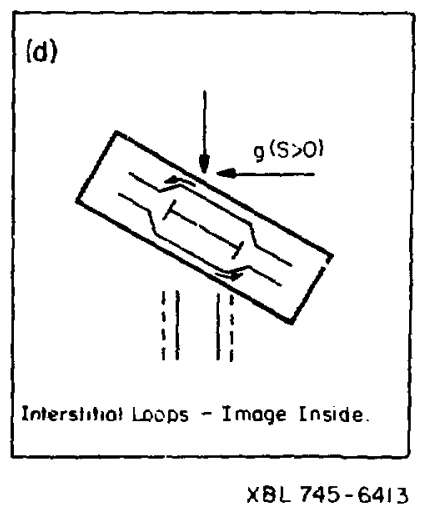

Fig. 4.7. 
on inclined planes. This indicates that stress aided or stress inhibited nucleation is not an important factor in the annealing process despite the large internal stresses $\left(2 \times 10^{19}\right.$ dynes $\left./ \mathrm{cm}^{2}\right)$ that have been reported (Ernisse, 1969).

The special contrast effects, namely the great change in outside to inside contrast in Frank loops (Fig. 4.6b,C) and the dark interiors of perfect loops (Fig. 4.6b at $B$ for instance) are discussed in the next section. There it is concluded that this could indicate dopant atom segregation to the stacking fault. This could result in a small change in the displacement vector of the Frank loops from $a / 3\langle 111\rangle$ to $a / x\{111>x>3$ and that of the perfect. loops from $a / 2[110]$ to $a / 2[110]-a / y[111]$. This is discussed in mare detai] in Chapter V.

\subsection{Contrast Effects-Depth Distribution}

It was mentioned in Section 4.2.2 that the perfect loops showed very dark inside contrast and weak outside contrast (see Fig. 4.1). This has been previously noted by Davidson and Booker (1971) who were the first to ascribe it to precipitation at or near the loop. They did not suggest any mechanism by which this may occur, however. This effect ic also seen in some recent images (Bickne11, 1973); this author does not draw any specific inference from the effect.

In this study, the perfect loops as well as the Frank loops showed the contrast effect mentioned above, both in bright field (Fig. 4.8) and in weak beam (Fig. 4.9). In Fig. 4.8a the foil was imaged at the 111 pole with $\hat{g}=02 \overline{2}$ so that the loops in the foil plane $(R \delta=11\})$ are not visible except by residual contrast $(\hat{g} \cdot R \delta=0)$. In Fig. $4.8 b$ and $\mathrm{c}$ they are inaged with $\mathrm{g}+$ and $-\overline{1} \overline{1} \bar{l}$ at the [112] pole. The great 
difference in inside and outside contrast is obvious. The same is true for the weak-beam images (Fig. 4.9). For instance, Frank loops formed by quenching pure alumirum (Eddington and Smallman, 1965) and examined with $\mathrm{g}=$ tor $-[111]$ do not shaw this great change in contrast. Frank loops formed by quenching pure aluminum (Eddingtan and Smal?man, 1965) and examined with $\pm g=111$ do not show this change in contrast.

One possibility is that this is a depth related effect: that the defects at a certain depth show dark contrast while those at another show weak contrast. In order tn check if this was so, the depth in the foil of several loops in the foil plane and of those on inclined planes were determined by stereomicroscopy and subsequent parallax measurement. The results are shown in Fig. 4.10. The loops in the foil plane lie wel? distributed within a depth of $1500 \AA$. Since most of the loops in the field of view show the effect, this is probably not a depth effect but a property of the defects themselves.

Another explanation is that the uniform contrast occurs by the overlap of dislocation taıls (Low and Turqualo, 1968). " However, such an overlap should not depend upon the sign of $(\tilde{g} \cdot \tilde{b}) s$. Since the contrast from these defects do, this explanation is perhaps not adequate.

The similar contrast effects observed in the Frank loops and described in Section 4.2 .3 is, therefore, interpreted as structure factor contrast arising from impurities adsorbed on the stacking fault. The contrast effect observed in the perfect loops could then be explained on the basis that the adsorbed atoms remain after the loop has unfaulted.

\footnotetext{
I am grateful to Dr. M. J. Goringe for this suggestion.
} 


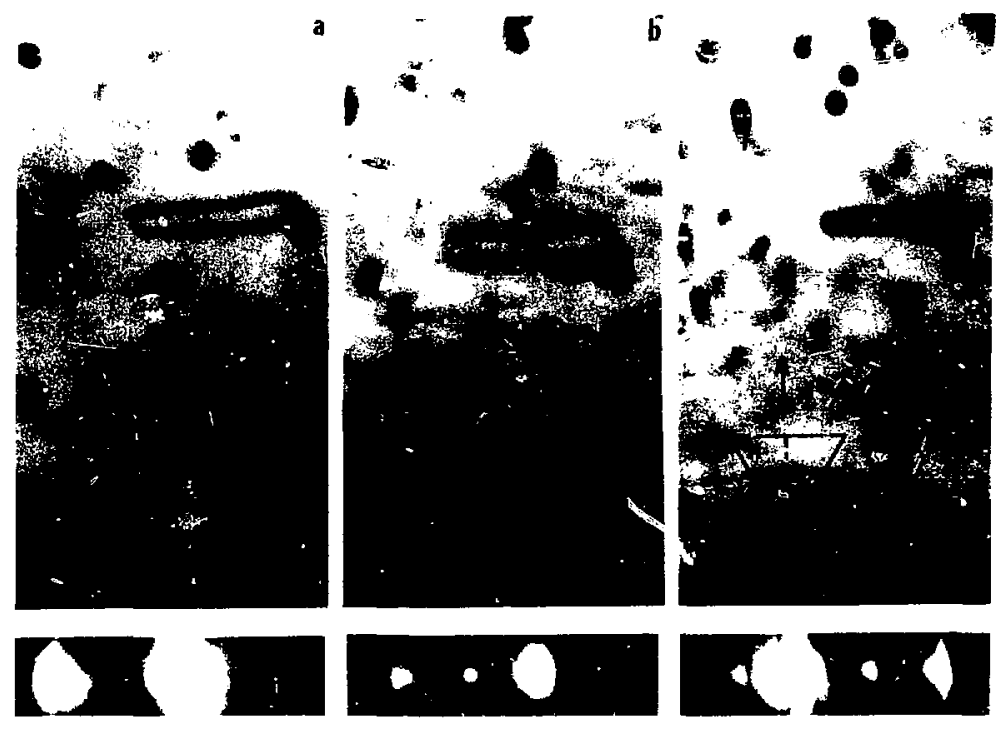

XBB 7410-7194

Fig. 4.8. To show the great difference between inside and outside contrast shown by loops. (a) Shows the lnops in residua? contrast, (b) shows the loops in weak outside contrast and (c) shows the loops in strong inside contrast. inis is not a depth effect (see text); it could arise from the segregation of impurity to the loops. 

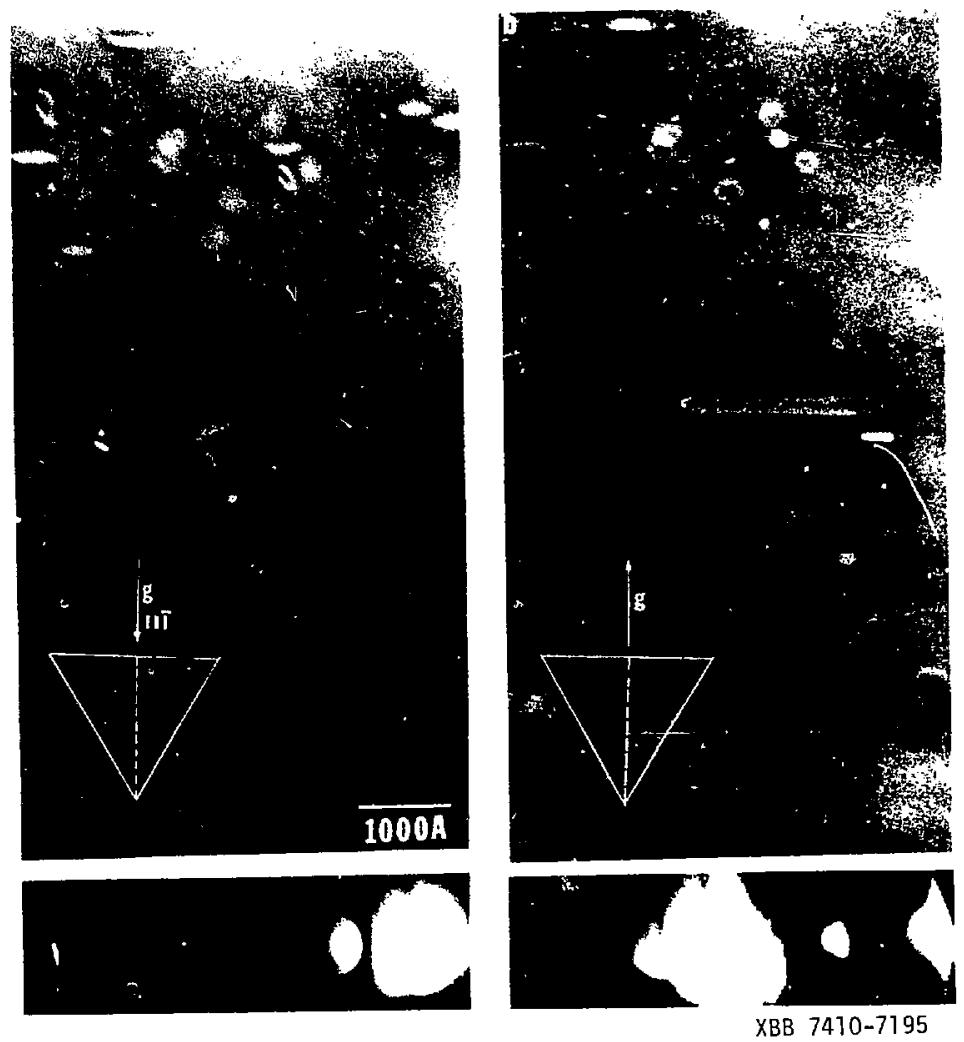

Fig. 4.9. The same images in $! g$ in two weak beam conditions:

(a) $(g, 4 g s+)$ (b) $(-g,-3 g s+)$. The loops show faint outside contrast in (a) and strong inside contrast in (b). The effect does not depend on "s" but only on the sign of $(g \cdot b) \mathrm{s}$. 


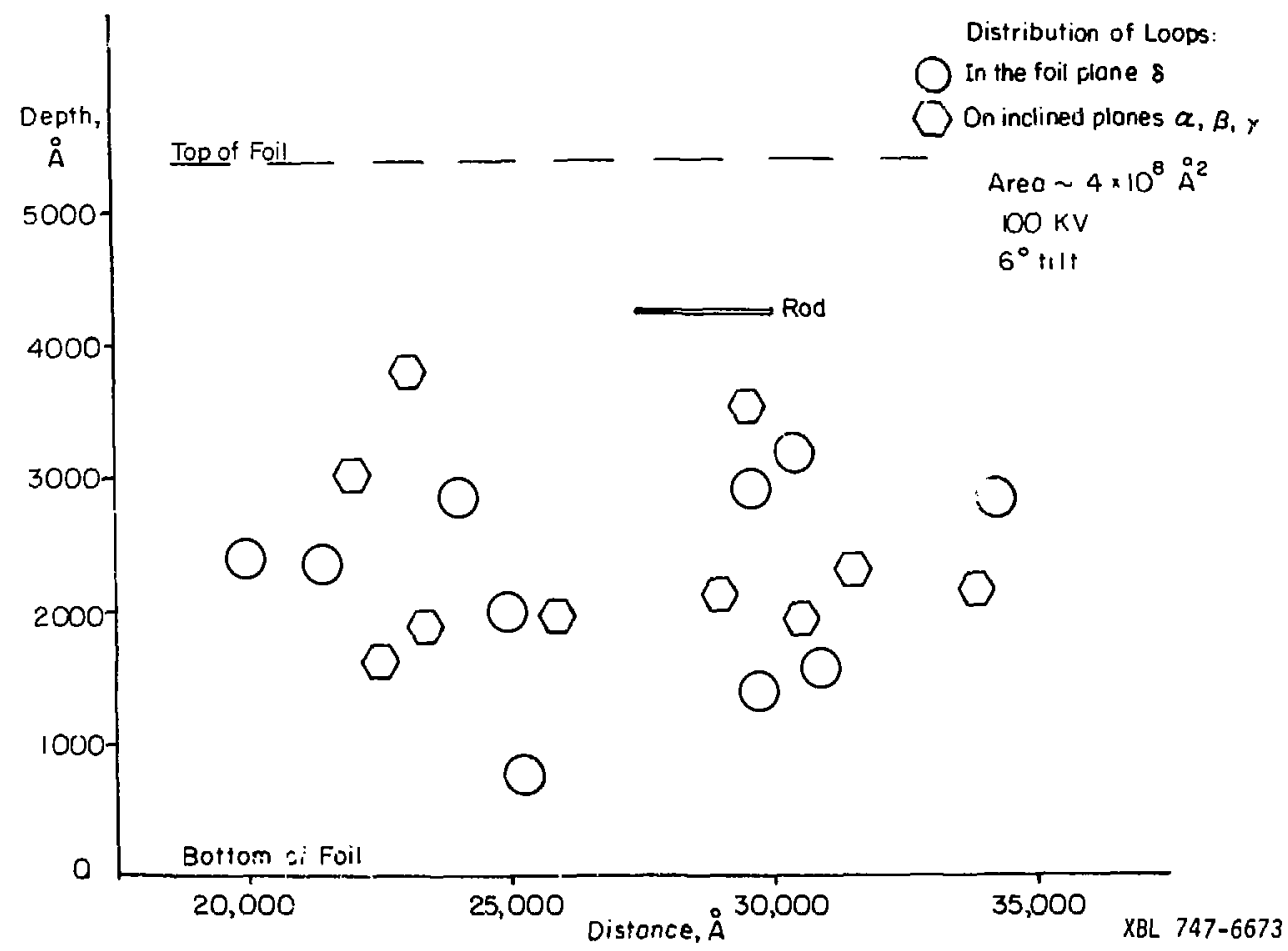

Fig. 4.10. Distribution of loops in the foil plane compared wit! the distribution of those on inclined planes. The $\delta$ loops are uniformly distributed over a depth of about $3000 \AA$. 


\subsection{Defect Morphology-Silicon Prehistory}

Descriptions of defect morphology for annealed $\mathrm{P}^{+}$ion implanted silicon are varied as is explained in section 4.1; the origin of this variation is not clear. In order to investigate whether the presence of piror dopants in silicon alter the defect morphology $\mathrm{P}^{+}$ ions were implanted into

a. $n$ type (phosphorous doped) 111 silicon

b. $n$ type ?phosphorous doped) "lopex" (1ow oxygen) 111 siiicon

c,d. n type (antimony doped) 111 silicon

(The letters cor: espond to Fig. 4.11.)

In addition, two p (boron) doped silicon wafers, one implanted with $\mathrm{P}^{+}$and the other with $\mathrm{SiH}^{+}$ions were examined. The substrates were all about $1 s \mathrm{~cm}$ and the dose was $2 \times 10^{14}$ ions $/ \mathrm{cm}^{2}$ in all casies.

The defects formed in $\mathrm{P}^{+}$and $\mathrm{si}^{+}$implants were not very different from each other. Frank loops and linear defects were observed. Fewer defects were observed in the $\mathrm{SiH}^{+}$implants. A possible explanation is that damage is sensitive to size of the implanted ion.

Defects observed after annealing the n-type foils were different from those in the $p$ (typ2) foils and from each other as shown in Fig. 4.11. The fraction of larger and more circular loops was greater in $n$ type fails. These were examined at the $(\hat{g}, 3 \hat{g})$ weak beam condition and showed no fringes indicating that they were perfect. Also, no linear defects were observed. Figure $4.11 \mathrm{c}$ and $d$ shows that these loops al.o show very strong inside contrast (e.g., at $A$ in Fig. 4.10 C) and weak outside contrast, e.g., Fig. 4.1 id, suggesting some precipitation (Davidson and Booker, 1971). 

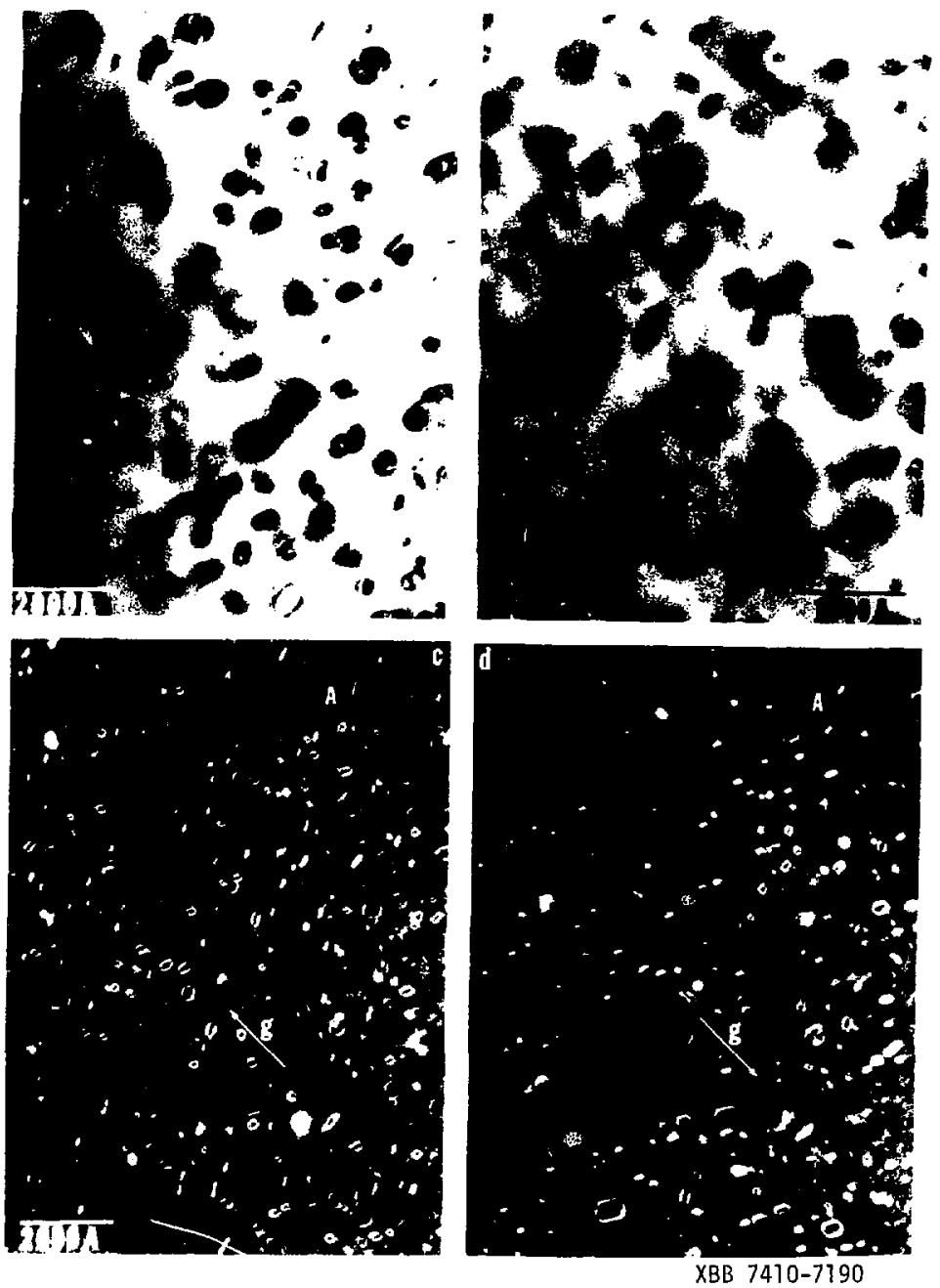

Fig. 4.11. A comparison of loop morphology when the dopants in the substrate are changed. Shown are $(a) n(P) S i,(b) n(P)$ lopex $S i$ (c,d) $n(s b)$ si all implanted with $p+$ ions $\left(2.1014 \mathrm{i} / \mathrm{cm}^{2}\right)$ and annealed to $800^{\prime} \mathrm{C}$ for $2 \mathrm{~min}$. Linear defects are not formed. The loops are larger, circular and mostly perfect. 
The possibility that dopants may be adsorbed on the stacking fau': provides a simple explanation not only for the contrast effects observed but also for the relatively poor electrical activity of foils containing such Frank loops reported by Crowder and Moreheat (1969).

These ideas are further developed in Chapter $V$.

It was concluded from this experiment that defect morphology resulting trom phosphor us implantation and annealing is sensitive to the presence of solutes. The presence of larger dopant atoms phosphorous and antimony, favored the growth of perfect loops. A possibility is that the higher internal stress, associated with atoms of larger misfit, promotes nucleation of perfect loops or unfaulting of Frank loops.

Since linear defects were only observed in foils containing boron (e.g., $\mathrm{B}^{+}$implanted foils and $\mathrm{P}^{+}$implants in boron doped foils) and absent when no boron was present (e.g., in $n$ ( $P$ doped) and $n$ (sb doped) foils as above), it was concluded that boron is necessary for growth of linear defects.

The annealing behavior and depth distribution of 1 inear defects is described in the next section.

ॠ I am grateful to Dr. Westmecott for this suggestion. 


\subsection{On the Presence of Linear Defects}

Chadderton and Eisen (19:1) showed that for room temperature $B^{+}$ implantation "rod-like" linear defects were formed along the [110] directions. These foils showed an increase of electrical activity which coincided with the disappearance of the rods. It was concluded that $B$ was associated with these defects.

Bicknell (1973) rejurts that linear defects were absent in $\mathrm{P}^{+}$ implants. This was correlated with the absence of any abnormal increase in the carrier concentration vs annealing temperature curve implying that $\mathrm{P}^{+}$dopants do not form linear defects. In contradiction to this linear defects were found in $\mathrm{P}^{+}$implants used in this study (Seshan and Washburn, 1972). Tamura and Ikeda (1972) reported 1 inear defects in high temperature $\mathrm{P}^{+}$implants (1974). More recently, Madden (1973 has reported the presence of livisar defects in $\mathrm{P}^{+}$implants at rim temperature.

The experiments described below were done to study the linear defects in more detail. In Fig. 4.12 a foil is shown which was partly masked from the ion beam, annealed at $800^{\circ} \mathrm{C}$ and then examined. Loops and linear defects formed only in irradiated areas. This experiment eliminates the possibility of contamination from the furnace atmosphere; the defects are associated with the damage process. Similarly, foils were heat treated in different furnace atmospheres e.g., a $4 \% \mathrm{H}_{2}-96 \%$ He mixture, and in extra pure helium and the specimen cooling rate was changed; wafers of 111 and 100 were also used. Linear defects were found in all p-type foils regardless of orientation and heating procedure. It was also confirmed by examining epi on epi wafers that the mechanical polishing of silicon prior to implantation does not affect linear defect formation. 

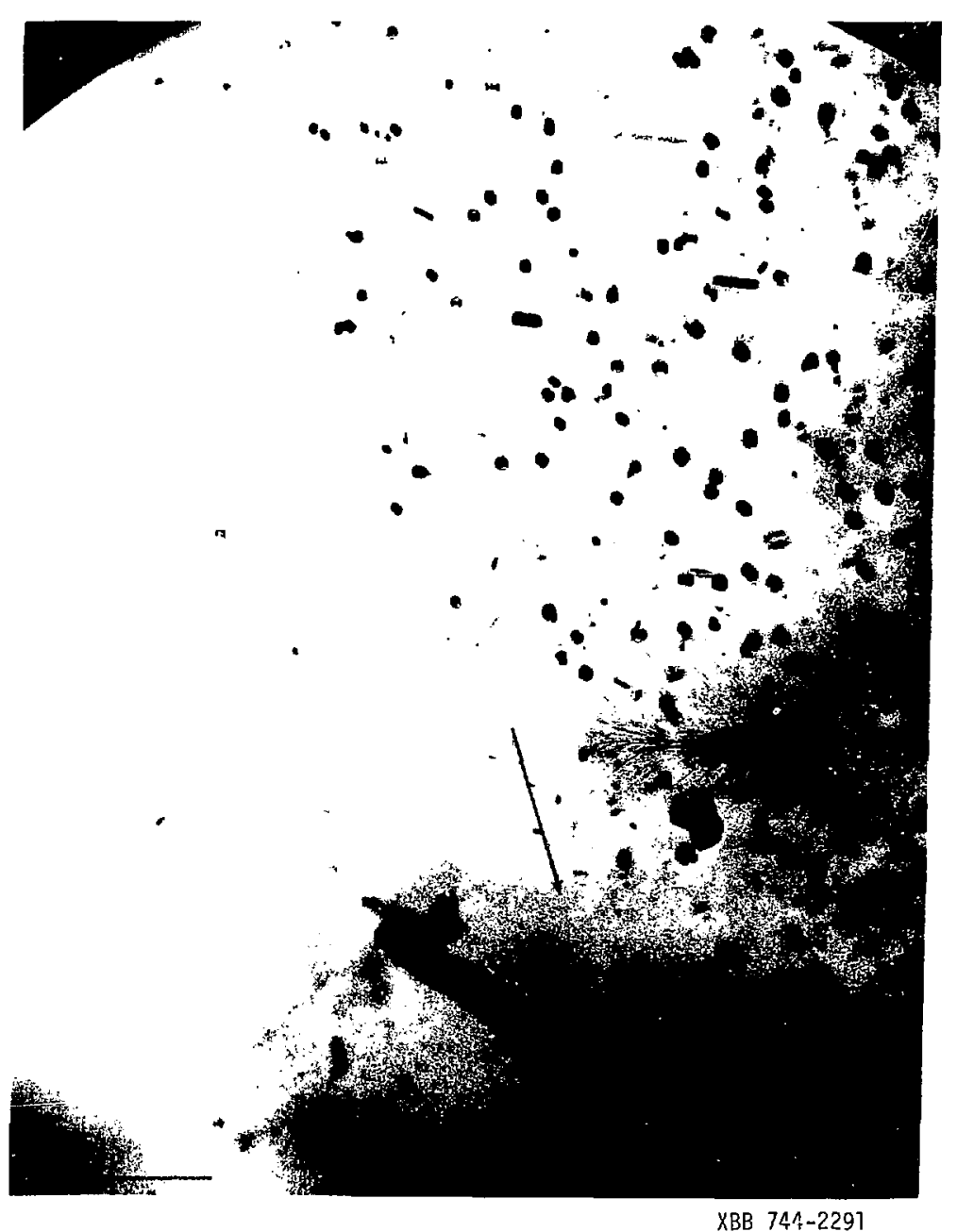

Fig. 4.12. Shows an area partially exposed to the ion-beam. Subsequent annealing shows that no defects form in the areas not bombarded. The possibility that furnace contaminents affect defects is eliminated. 
Linear defects were observed only in foils containing boron (Section 4.3). It was, therefore, concluded that boron was necessary for the linear defects to form (Seshan and Washburn, 1975).

The result that 1 inear defects are formed in hot implants (Tamura, 1971) is interesting in that it suggests that foil heating is important. The claculation in Chapter II shows that beam heating can be a problem if a good heat sink is not provided. The temperature rise of the foils examined in this study was not expected to be over $50^{\circ}$ (Reddi, 1974). However, foils implanted using different types of heat sinks were not examined.

In order to study the annealing behavior, depth distribution data was obtained for rods and loops using stereomicroscopy. Foils were tilted $6^{\circ}$ along the $g=220$ Kikuchi band and images under identical diffracting conditions were obtained. Parallax measurements were made using a Wilde parallax bar and sterescope. The depth distribution of defects in a foil annealed at $800^{\circ} \mathrm{C}$ for $1 / 2 \mathrm{hr}$ is seen in Fig. 4.13 . No defects are seen within $1000 \AA$ from the implanted surface. (This is marked "top of foil" in Fig. 4.13.) This is consistant with theory that the incoming ions cause no damage for the first $1000 \AA$ where they suffer electronic collisions. The defects loops and linear defects are then distributed in a $3000 \AA$ g $=e$ layer where the ions suffer nuclear collisicns, and come to rest, causing severe lattice damage.

The inclined rods along the three inclined [110] directions extend (from the layer of the loops) to the implanted surface. Cepth distribution in another foil heated at $650^{\circ} \mathrm{C}$ for $2 \mathrm{hr}$ is shown in Fig. 4.14. 


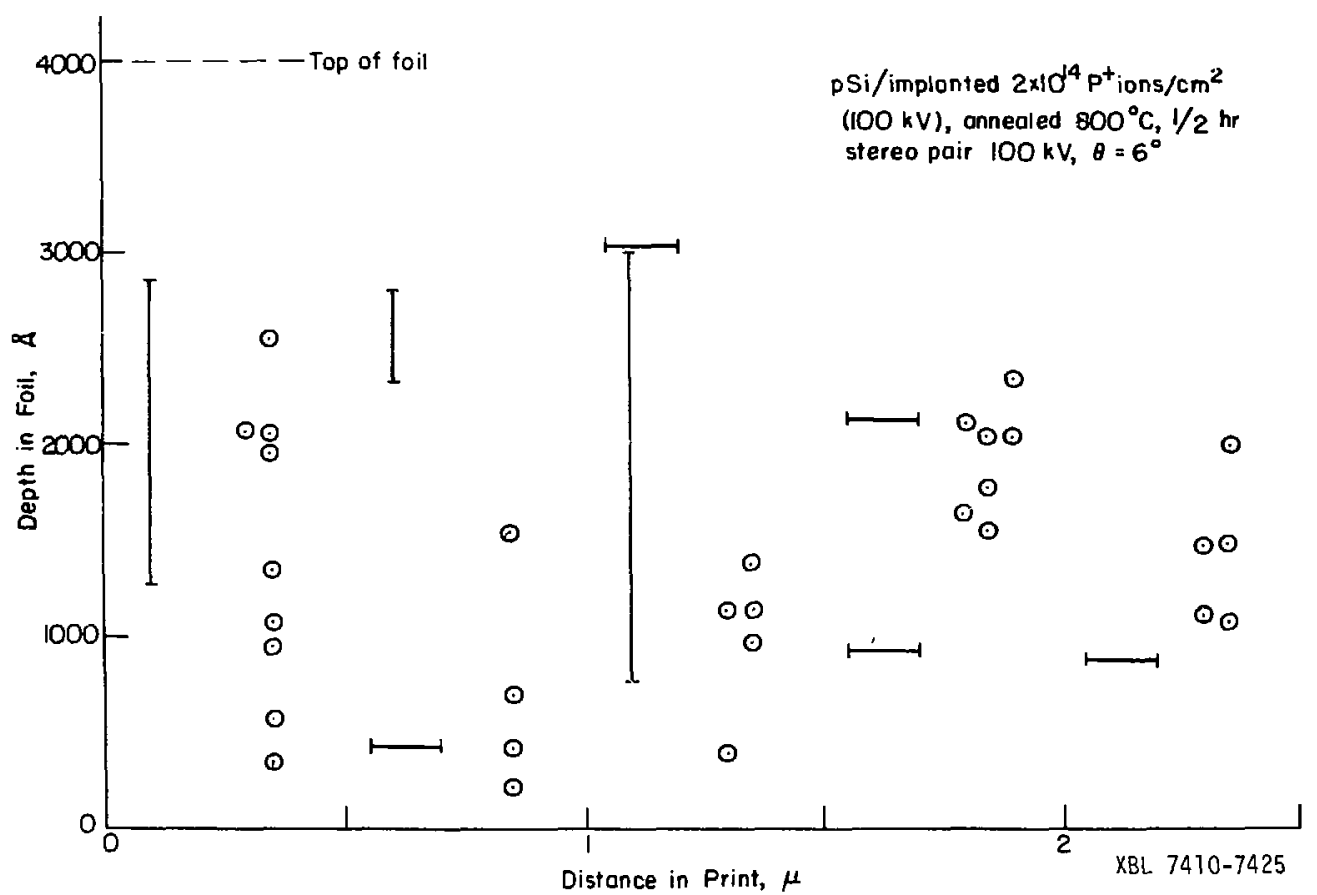

Fig. 4.13. A stereo-microscopic depth determination of linear defects and loops in a foil annealed at $800^{\circ} \mathrm{C}$ for $1 / 2 \mathrm{hr}$. The defects incilined to the foil surface (drawn vertically in this diagram) are longer than those in the foil plane. 


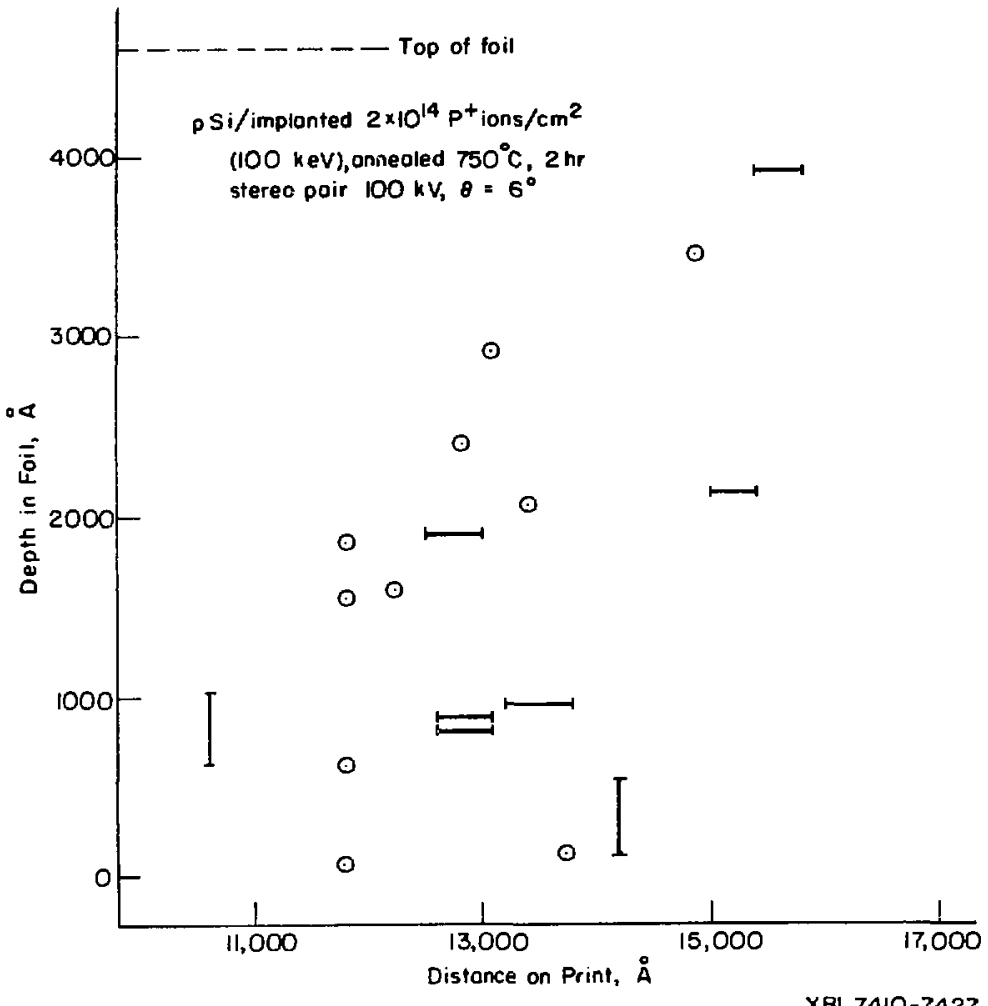

Fig. 4.14. Depth distribution of linear defects and loops in a foil annealed for a longer time than in Fig. 4.13. The 1 inear defects inclined to the foil surface appear greatly reduced in length. The shrink by point defect emission to the top surface. 


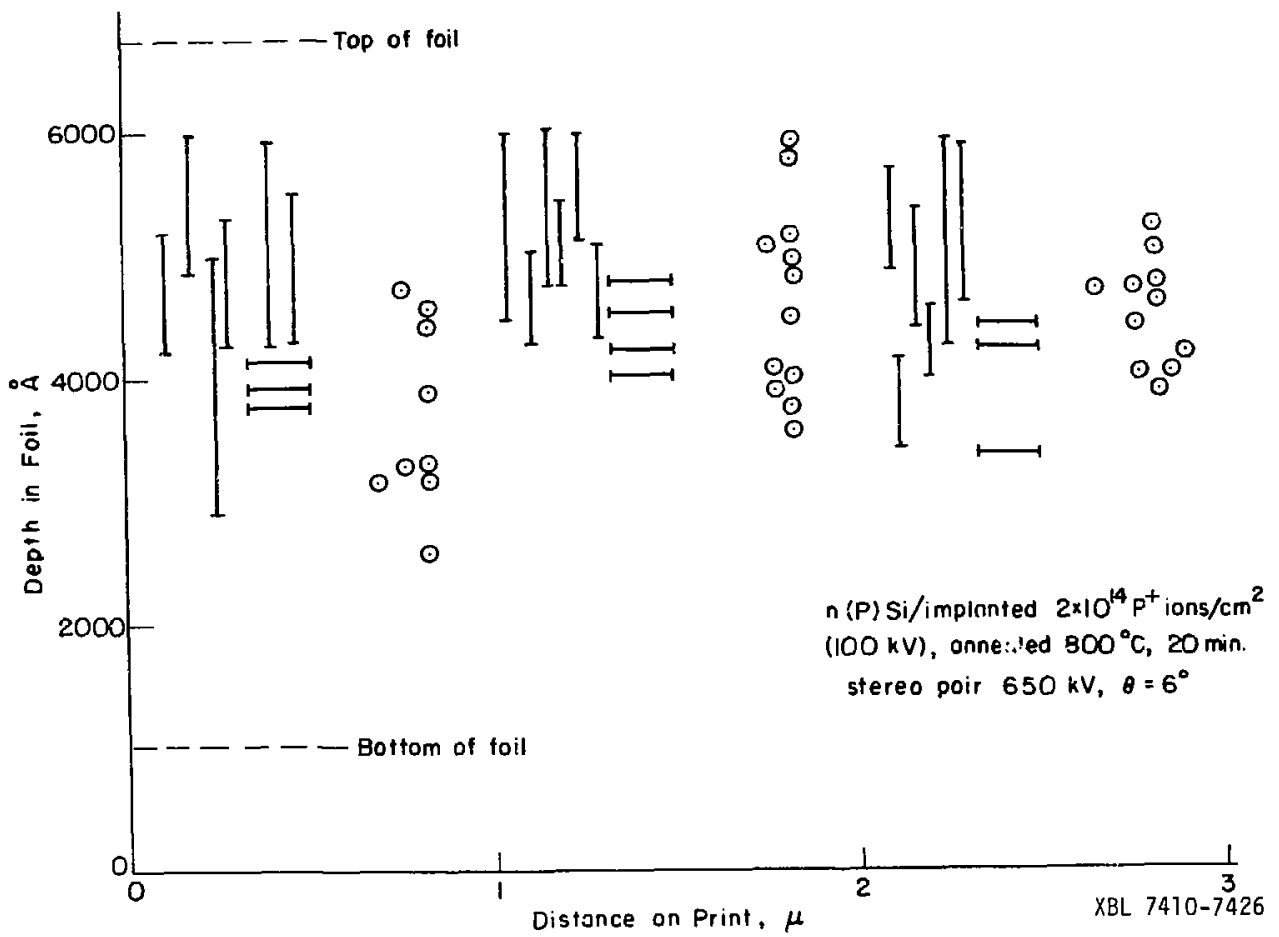

Fig. 4.15. Stereo depth distribution as determined in the high voltage electron microscope. The 10ops and the linear defects parallel to the foil surface lie distributed roughly over the same depth. The inclined defects extend from the layer of the loops to the top surface. There are no interactions between the rods and loops suggesting they are both interstitia?. 
Notice that the inclined linear defects have shrunk back from the end near the top surface. This suggests that they shrink by the emission of point defects to the free surface.

The advantage afforded by the greater penetration of the $650 \mathrm{kV}$ electron microscope is illustrated by Fig. 4.15. The loops and the horizontal defects are distributed in the same depth region whereas most of the inclined rods extended to the top surface. It is also significant that the loops and the 1 inear defects do not often interact. They probably compete for the same point defects and hence avoid each other during nucleation and growth. The linear defeits nust then be interstitial. This is also the conclusion of Madden and Davidson (1973) based on contrast analysis. 


\subsection{Dijcussion and Conclusions}

For ion implantation doses where a continuous amorphous layer is not formed, defects in p-type $\mathrm{P}^{+}$ion implanted silicon are hexagonal interstitial Frank loops. Interstitial linear defects and a few perfect loops are also found. In n-type foils linear defects are not formed indicating that boron is necessary for their formation. The morphology of the loops depends upon the dopant atoms present in the s-licon prior to implantation. The loops also show contrast effects indicative of precipitation within the loop. It is, therefore, likely that the dopant atoms interact with the defects--incluciing adsorption on the stacking fault within the Frank loops. This interaction may explain the contrast effects shown by perfect loops and is also an alternative explanation for the electrical inactivity of $\mathrm{P}^{+}$ions in these foils (Chapter $V$ ). 
CHAPTER $V$.

A MODEL FOR THE PRESENCE OF INTERSTITIAL DEFECTS

5.1. Introduction . . . . . . . . . . . 74

5.2. Model .................. 77

5.3. Applications of the Model ................ 91 
"Absence of evidence is not evidence for absence."

Anon

\subsection{Introduction}

Measurements of resistiuity and carrier concencration in isochronally annealed non-implanted silicon shows that there is a rapid recovery of electrical conductivity in the $550-600^{\circ} \mathrm{C}$ range (Bicknel and Allen, 1971; Davidson and Eooker, 1971). Infrared absorption (Vook and Stein, 1970; Cheng et al., 1966) and EPR studies irradiated silicon (Watkins, 1965) shows that vacancies are formed and are mobile at room temperature. Upon heating they anneal out at about $300^{\circ} \mathrm{C}$. At this temperature there is a large increase in the numbers of divacancies and vacancy dopant complexes. These annealed out in the $500-600^{\circ} \mathrm{C}$ range. From a consideration of such studies, the presently held view of the annealing process is as follows:

a. At or below room temperature motion of vacancies control the formation of damage clusters (Vook and Stein, 1970).

b. Upon heating in the $300-400^{\circ} \mathrm{C}$ range these initial damage clusters anneal by the liberation of vacancies; these then coalasce to form divacancies and more stable vacancy dopant complexes (Mayer, 1971).

c. Upon heating to $400-600^{\circ} \mathrm{C}$ the divacancies and vacancy-dopant complexes "arineal out"; dopant atoms become substitutional and hence electrically active (Bicknell, 1971). However, in the case of $\mathrm{P}^{+}$implants in the $10^{14}$ ions $/ \mathrm{cm}^{2}$ range; only $30 \%$ of the implanted atoms are electrically active after a $600^{\circ} \mathrm{C}$ anneal (Crowder and Moreheac, 1969). 
d. electrical inactivity of the dopants in the early stages occurs by vacancy compensation (Vook .... Stein, 1970).

The above explanation besides ignoring the role of the interstitial, gives no suggestion as to what happens to the divacancies when they anneal out. In Chapter I it was pointed out that the interstitial in silicon is still undetecteo. However, it is unreasonable to expert that they do not form as the damage event produces Frankel pairs i.e., interstitials and vacancies in equal numbers.* There have bien several suggestions that the vacancies cluster to form higher order defects (Chadderton and Eisen, 1971; Brack et al., 1973). However, if this is the case, some vacnacy type defects ought to be observed.

The contrary is suggested by the present electron microscope studies. The defects formed on the anneating of iron implantation damage are all interstitial type (Chapter IV). This is also the resuit obtained by other workers using different implanted ions iniluding $\mathrm{P}^{+}, \mathrm{B}^{+}$and $\mathrm{As}^{+}$(Jenkins at al., 1973);

Another problem arises when the number of point defects involved in the damage pracess is considered. Some relevant numbers are given below for a typical $100 \mathrm{keV}$ implant:

number of atoms displaced per incident $\mathrm{p}^{+}$ion: 1000 average number of point defects per $\mathrm{cm}^{-3}$ upon bombardment:

In addition to the atoms implanted which comprise under $0.1 \%$ of the defects produced. 


$$
\begin{array}{ll}
\begin{array}{c}
\text { number of Frank loops per } \mathrm{cm}^{-3} \text { upon } \\
\text { annealing: }
\end{array} & 10^{13}-10^{15} \begin{array}{c}
\text { (Davidson 1970 } \\
\text { Maduen 1973) }
\end{array} \\
\text { number of atonls in loops of size 300A: } & 10^{3} \\
\text { loops per } \mathrm{cm}^{-3}: & 10^{16}-10^{17} \\
\text { number of } \mathrm{P}^{+} \text {ions implanter per } & 2 \times 10^{14} \mathrm{~cm}^{-2} \text { or } 2 \times 10^{18} \mathrm{~cm}^{-3}
\end{array}
$$

if $10^{22}$ Frenkel pairs form and subsequently annihilate, an excess of $10^{16}-10^{18}$ interstitials per $\mathrm{cm}^{-3}$ from which the loops are formed have to be accounted for.

It is significent that this is a smal) fraction $\left(10^{-5}\right)$ of the Frenke] pairs originally profuced and is of the some order as the number of dopant atoms implanted.

Clearly a model for the annealing process is required. The mode] ought to explain the presence of the interstitial defects as well as account for the annealing of divacancies in the $500^{\circ} \mathrm{C}$ range. It should assume that Frenkel pairs are produced by ion damage. 


\subsection{Model}

Stage I Room temperature As implanted

In order to develop a model for the annealing process it is necessary to know the formation and migration energies of the point defects involved. In Table 5.1 the relevant information is listed. From this it is evident that at this stage (Stage I) the elementary interstitials and vacancies are mobile. In this model it is proposed that the interstitials travel away from the damaged zone and form submicroscopic clusters in the surrounding crystai. The compressive stress experienced within the damage zones due to their expansion (Tu et al., 1972) is of the order of $10^{19}$ dynes $/ \mathrm{cm}^{2}$ (Ernisse, 1971). This compressive stress promotes the drift of interstitials away from the amorphous zones into the less damaged regions the slower moving vacancies either annihilate interstitials or complex with each other to form divacancy and vacancy dopant complexes. The result would be a central damaged regicn rich in vacancies as proposed for metals (Nelson, 1969). Room temperature EPR evinces a high concentration ( 5 per ion) of divacancies in the heavily damaged crystal as shown in Fig. 5.1 (Vook and Stein, 1969; Daley, 1969). A large fraction of the $10^{22}$ Frenkel pairs per $\mathrm{cm}^{3}$ (1000 per ion) annihilate. As suggested by the investigators the measured divacarcy concentration of five per ion is probably an underestimate berause their method does not detect those vacancies incorporated in the core itself. Supposing as many as half the Frenkel pairs annihilate by direct recombination of vacancies and interstitials about $10^{20}-10^{19}$ vacancies and interstitials will remain at this stage. Interstitials which have formed small stable 


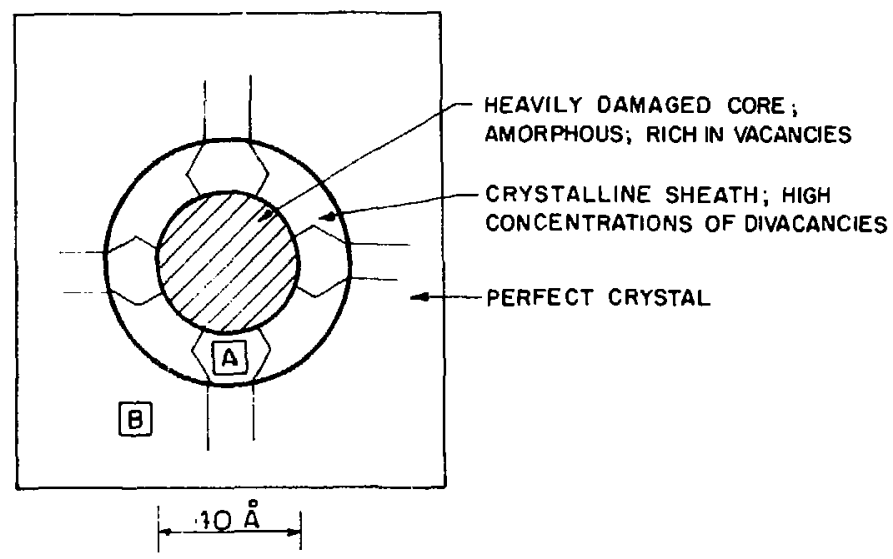

$\stackrel{\dot{0}}{\dot{1}}$

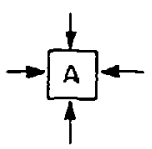

COMPRESSIVE STRESS IN DAMAGED REGIONS; FAVORS EXPULSION OF INTERSTITIALS

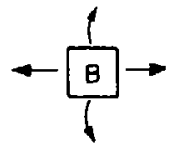

TENSION STRESS IN SURROUNDING CRYSTAL; FAVORS NUCLEATION OF SUBMICROSCOPIC INTERSTITIAL CLUSTERS $\sigma_{T}=10^{7}$ DYNES/ $/ \mathrm{CM}^{2}$ X BL 7412-7632

Fig. 5.1. Shows a model of a damage duster formed at the end of an ion track. Interstitiais are expelled from the regions ir: compression $A$ to incise in tension B where they may cluster. 
clusters probably also incorporate those dopant atoms not al ready complexed with vacancies.

Other workers have suggested the existance of submicroscopic clusters. Based on X-ray lattice parameter data clusters of interstitials and vacancies have been suggested in neutron irradiated silicon (Baldwin, 1965). More recently law temperature photoluminescence investigations of ion implanted silicon have shown evidence of interstitial clusters. However, the constituants of the clusters were not determined (Noonan et a1., 1974).

Stage II $300-600^{\circ} \mathrm{C}$

EPR evidence shows that this region corresponds to first the formation of numerous divacancies and at higher temperatures to their annealing out. In this model the central damaged regions are expected to repair by the emission of vacancies some of which form divacancies in the lower temperature ranges $300-400^{\circ} \mathrm{C}$. At higher temperatures 400-600 ${ }^{\circ}$ the divacancies (see Table 5.1) become mobile and annihiiate the interstitial clusters and complex with the dopant atoms.

Electron diffraction patterns of thin foils in the as received condition and after annealing to $400^{\circ} \mathrm{C}$ are shown in Fig. $5.2 \mathrm{a}, \mathrm{b}$ respectively. The faint rings in Fig. $5.2 \mathrm{a}$ indicate the presence of a high density of amorphous zones (the spots appear from the irystalline substrate). The rings disappear when the substrate is heat $=\dot{i}$ to $400^{\circ} \mathrm{C}$ (Fig. 5.2b). This is an agreement with EPR data that isolated amurphous zones anneal at $400^{\circ} \mathrm{C}$.

Trie viffriction pattern in Fig. $5.2 b$ shows pronounced streaking in the 111 directions as well as a set of 111 reflections. Figure 5.3 
shows how the streaks and spots can be correctly accounted for if each ¿20 reflection in the zero Laue layer (Fig. 5.3 at 8 ) and each 111 reflection in the first Laue layer (Fig. 5.3 at $A$ ) is extended in the four 111 directions.

(This is further illustrated in Fig. 5.4 which shows the zero and the first Laue layer in various projections. A "possible" shape of the cluster which could give rise to such extensions in reciprocal space is shown in Fig. 5.4C). A dark field image of the streaks (Fig. 5.5) shows small granular areas 50-70尺 wide. The streaks could then be ilterpreted as the rel-rods or planes in reciprocal lattice produced by small clusters on the four $\{11\}$ planes. The granular areas in Fig. 5.3 are evidently diffraction contrast produced by the clusters.

A possible alternative suggestion from a study of heavily damaged substrates (Matthews, 1971) is that the 111 streaks arise from high densities of "microtwins and faults". Upon annealing, such foils yield a complex defect structure of dislocation networks (Tamura, 1972; Madden, 1973). However, the substrates used in this study were damajed to below the critical dose where a continuous amorphous layer is not formed. Further the defects formed upon the annealing of damage are interstitial Frank loops. It is not possible to explain how "micro twins and faults" could age to produce a family of Frank loops. It is, therefore, reasonable to interpret the streaking as arising from small clusters on the close packed planes which, at higher annealing temperatures, combine to form Frank loops. 
It was not possible to determine the nature of these clusters that gave rise to rel rods in the early stages of annealing. Both interstitial and vacancy type could be present, about $10^{17}-10^{19}$ defects $1 \mathrm{~cm}^{3}$.

If small interstitial clusters do exist at $600^{\circ} \mathrm{C}$ it provides a possible explanation for the inactive dopants. According to EPR data most of the vacancy dopant complexes anneal out at this temperature. However, electrical measurements show only $50 \%$ dopant activity is achieved. It is proposed that the inactive dopant atoms are still complexed with the interstitial clusters at this stage.

Stabe III $600-800^{\circ} \mathrm{C}$

In the early stages the breais $u^{-}$of small interstitial clusters proceeds with the absorbed dopant atoms becoming substitutional. Most of the interstitials annihilate the remaining vacancy clusters. At the same time a few of the clusters, interstitial and vacancy, convert to Frank lowps on the close packed planes.

At this stage two effects which result in the formation of large interstitial loops and rod defects become significant. The first is the slightly higher strain interaction between the interstitial and the dislocation lines as compoind to that between a vacancy and the dislocation line. Consequently, dislocation loops will tend to trap a few more interstitials than vacarcies. This will tend to cause the vacancy loops to shrink and the interstitial loops to grow.

This effect alone might account for the predominance of interstitial loops, after high temperature annealing; the excess vacancies would be assumed to have reached the surface. 

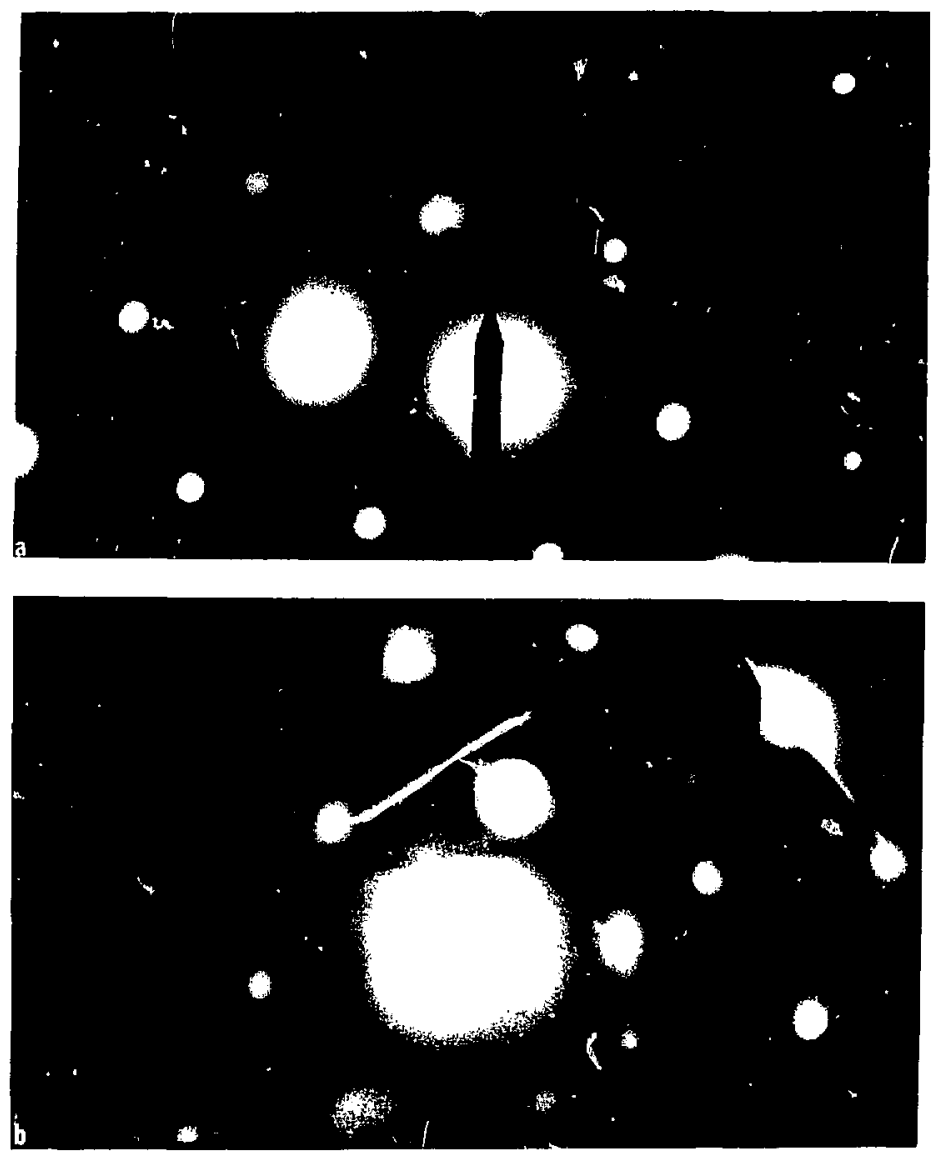

XBB $7411-7728$

Fig. 5.2. Diffraction patterns from (a) and as received sample (b) a sample annealed at $400 \mathrm{C}$ for $15 \mathrm{~min}$. In the as received samples faint rings from the amorphous layers were observed. Upon annealing (b) these faint rings disappear and well developed streaking in the 11,1 , directions and a set of $(111)$ spots were observed. 

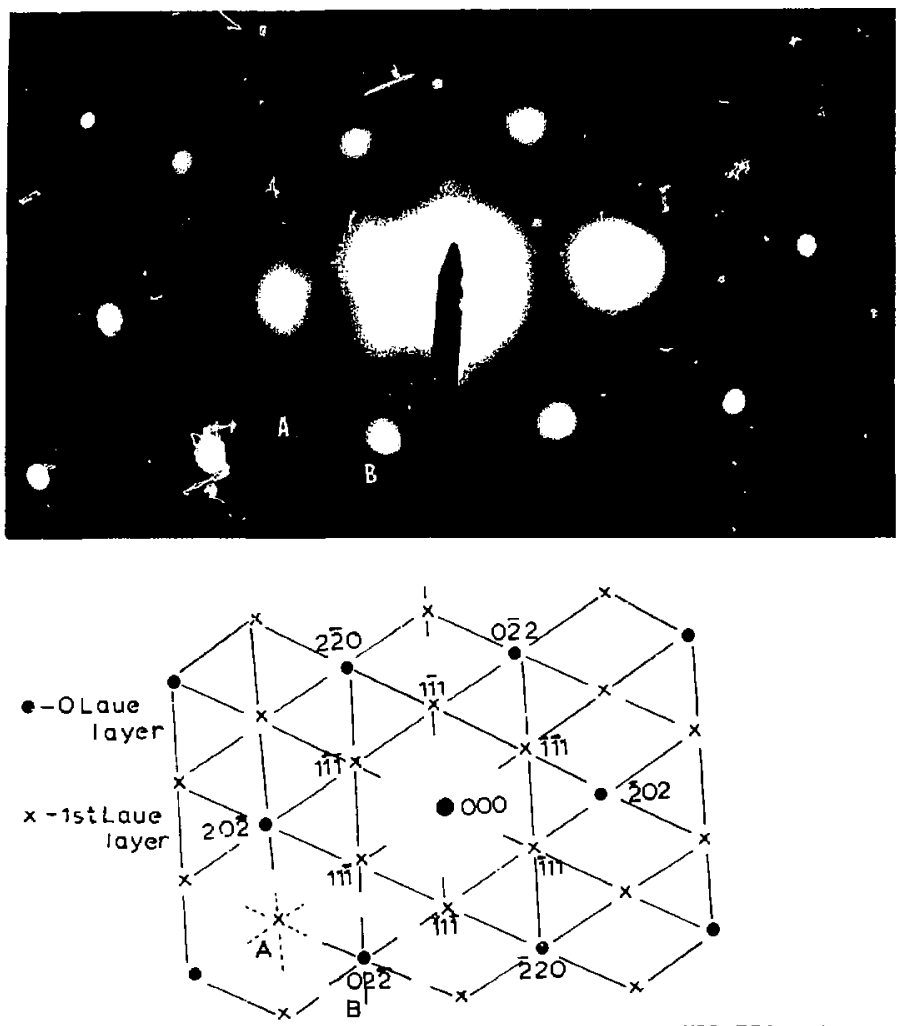

XBB 754-3248

Fig. 5.3. Shows how the streaks and the extra spots can all be accounted for by assuming that the $\{111\}$ spots of the first Laue layer $A$ and the 220 spots of zero Laue Tayer $B$ are extended in the fair (111) directions. 


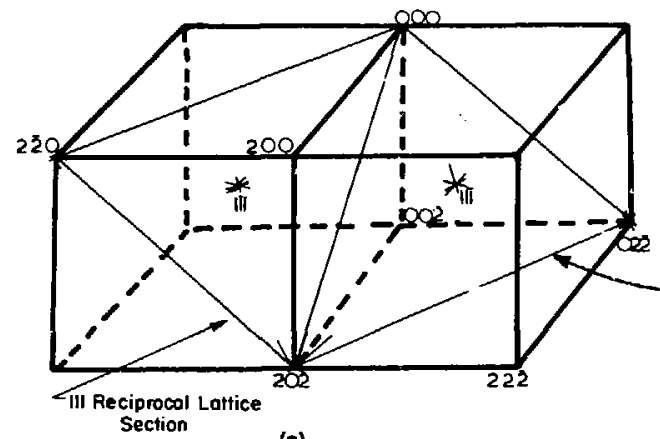

(o)

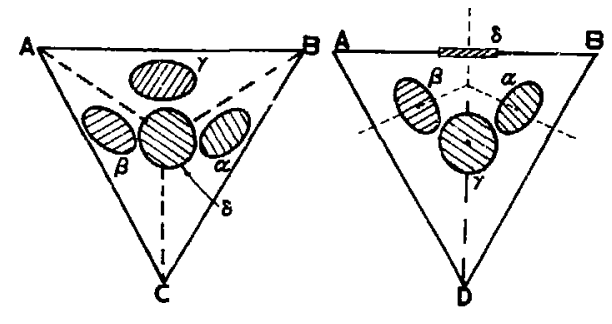

(c)

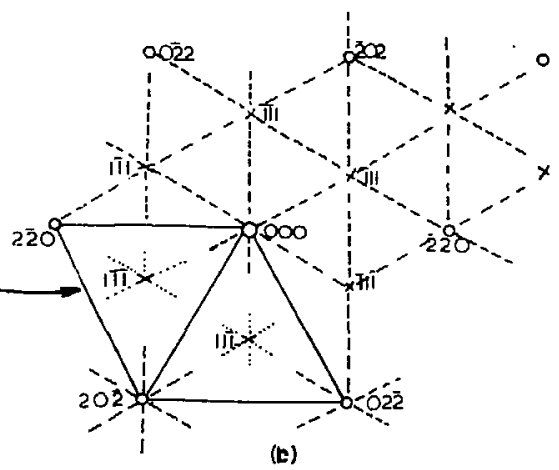

(c)

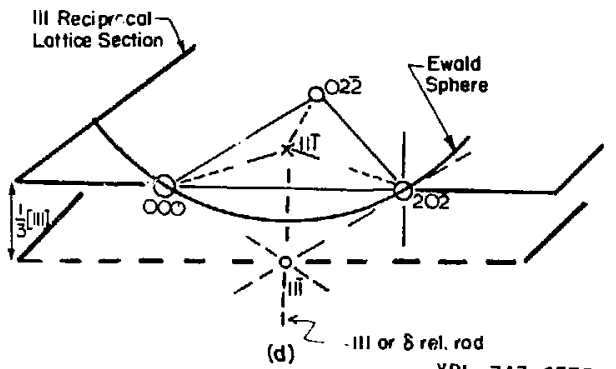

XBI 747-6779

Fig. 5.4 . (a) Shows the reciprocal lattice section of a fcc cell with the zero and the first Laue layer. give rise to such streaks.
(a) in the "ll1) direction. (c) Shows a "possible" cluster that could 

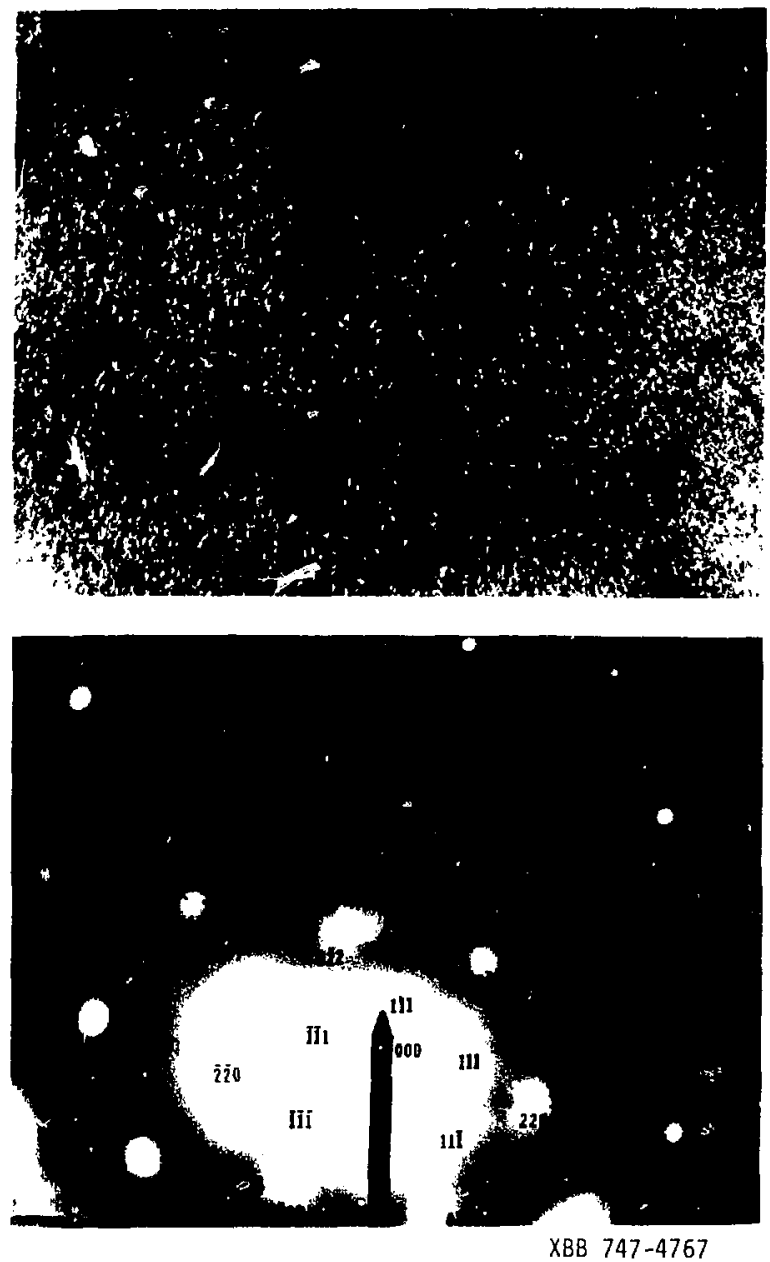

Fig. 5.5. Dark field image of the streaks showing the defect clusters that give rise to the streaking. It is argued (see text) that these could be small clusters of point defects which upon annealing at $800 \mathrm{C}$ give rise to Frank loops. 
However, the predominance of interstitial loops in these foils can also be explained in another way. It is assumed that when isolated amorphous zoles are found increase in the total number of lattice sites due to recrystallization of these zones. This is reasonable as long as a continuous amorphous layer has not been formed. Then as the dopant atoms become substitutional by combining with a various an equivalent number of silicon atoms must remain interstitial. Therefore, when all of the vacancy defects have been annihilated by recombining with interstitials there will still be some interstitials left. These would be just enough to account for the growth of the observed interstitial defects by conversion of a few of the original small interstitial clusters into frank loops.

In the $800^{\circ} \mathrm{C}$ range the well developed Frank loops with their enclosed stacking faults can still provide special sites for the remaining invactive dopants. The total number of interstitiais involved in the secondary defects is always less than the atoms displaced when the implanted dopant atoms become substitutional. This is in agreement with calculations performed in Boron implanted foils (Bicknell, 1969) where it was shown that the number of atoms in the loops equals roughly the number of dopants implanted.

Stage IV $800-900^{\circ} \mathrm{C}$

This corresponds to the highest temperiture ranges where the loops shrink under their own line tension. Seegar (1970) has proposed that at this temperature al interstitial diffusion mechanism operates. Vacancies could also be nucleated at the surface and migrate to the loops. 
In this temperature range, $100 \%$ electrical activity is finally attaines. This is explained on the basis that when the loops shrink the dopant atoms within the stackiny fault and dislocation cores finally come to occupy regular substitutional sites. A summary of the four stages is given in Table 5.2 . 
Table 5.1.

Formation and migration energy of point defects in silicon.

\begin{tabular}{|c|c|c|c|c|}
\hline & & Author & $\mathrm{eV}$ & Temperature at which Defects Anneal \\
\hline$E_{V}^{F}$ & $\begin{array}{l}\text { Energy of formation } \\
\text { of a vacancy }\end{array}$ & $\begin{array}{l}\text { Beriieman (1965) } \\
\text { Seeger-Chick (1968) } \\
\text { Seegar (1971) } \\
\text { Swal in (1972) }\end{array}$ & $\begin{array}{l}2.13 \\
2.97 \\
4.63^{\star} \\
2.0\end{array}$ & \\
\hline$E_{V}^{M}$ & $\begin{array}{l}\text { Energy of migration } \\
\text { of vacar.cy }\end{array}$ & $\begin{array}{l}\text { Watkins }(1965) \\
\text { Wähn }(1965)\end{array}$ & $\begin{array}{l}0.33 \text { Voneutral } \\
0.15 \mathrm{~V} \text { found in } \\
\text { n-type } S \mathrm{i} \\
0.16\end{array}$ & $\begin{array}{l}-300^{\circ} \mathrm{K} \\
70-85^{\circ} \mathrm{K}\end{array}$ \\
\hline$c_{V-V}^{F}$ & $\begin{array}{l}\text { Energy of formation } \\
\text { of a divacancy }\end{array}$ & Seeger \& Chick (1968) & 4.66 & \\
\hline$E_{V-V}^{M}$ & $\begin{array}{l}\text { Energy of migration } \\
\text { of divacancy }\end{array}$ & Stein (1971) & $\begin{array}{l}13 \\
0.4 V-V= \\
0.25 V-V=\end{array}$ & $\begin{array}{l}600-700^{\circ} \mathrm{K} \\
550^{\circ} \mathrm{K}\end{array}$ \\
\hline$E_{V-V}^{B}$ & $\begin{array}{l}\text { Binding energy of } \\
\text { divacancy }\end{array}$ & Seeger \& Chick (1968) & 1.27 & \\
\hline$E_{I}^{F}$ & $\begin{array}{l}\text { Energy cf formation } \\
\text { of interstitial }\end{array}$ & Benneman (1965) & 1.09 & \\
\hline
\end{tabular}


Table 5.1. Continued.

\begin{tabular}{|c|c|c|c|c|}
\hline & & Author & $\underline{\mathrm{V}}$ & Temperature at which Defects Anneal \\
\hline$E_{I}^{M}$ & $\begin{array}{l}\text { Energy of } \\
\text { Migration of an } \\
\text { Interstitial }\end{array}$ & $\begin{array}{l}\text { Seegar (1971) } \\
\text { Bennerian (1975) } \\
\text { Hasiguti }(1966) \\
\text { Watkins (i965) }\end{array}$ & $\begin{array}{l}0.85 \\
0.51 \\
<0.22 \\
\sim 0 \text { p-type } \\
\sim 0.4 \text { n-type }\end{array}$ & $\begin{array}{l}\text { Room Temperature } \\
\qquad \begin{aligned} & \sim 4.2^{\circ} \mathrm{K} \\
& \sim 170^{\circ} \mathrm{K}\end{aligned}\end{array}$ \\
\hline
\end{tabular}

\section{*alculated}

K. H. Benneman, Phys. Rev. 130, 1763 (1963).

R. R. Hagiguti, J. Phys. Soc. Japan 21, 1927 (1966).

A. Seeger and K. P. Chik, Phys. Stat. Sol. 29, 455 (1968).

A. Scholz-A. Seeger, Phys. Stat. Sol. 3, 14 $\overline{30}$ (1963).

A. Seeger, Rad. Eff. 9, 15 (1971).

H. J. Stein, Rad. Eff. 9 , 195 (1971).

R. A. Swal in, Thermodynamics of Solids (J. Hiley, N. Y., 1972), p. 299.

r. E. Wahn, Phys. Rev, 140, A690 (1965).

G. D. Watkins, Radiation Damage in Semiconductors (Dunod Paris, 1965), p. 97. 
Table 5.2. Surmary of the four stage process leading to interstitial defects in ion implanted silicon.

\begin{tabular}{|c|c|c|c|}
\hline Stage & Interstitial & Vácancies & Temp. \\
\hline I & $\begin{array}{l}\text { Incerstitials mobile } \\
\text { during implant. Anni- } \\
\text { hilate vacancies. Form } \\
\text { interstitial clusters. } \\
\text { Affected by stresses in } \\
\text { damaged layer. } 1022 / \mathrm{cm}^{3} \\
\text { defects fomed. } \sim 1019 / \mathrm{cm}^{3} \\
\text { defects in clusters. }\end{array}$ & $\begin{array}{l}\text { Form divacancies } \\
\text { annihilated. Form } V-P \text {, } \\
V-0 \text { complexes. }\end{array}$ & $\begin{array}{l}\text { Room } \\
\text { Temp. } \\
\text { to } 300^{\circ} \mathrm{C}\end{array}$ \\
\hline I I & $\begin{array}{l}\text { Interstitial clusters } \\
\text { stable; some break up and } \\
\text { are annihilated. Associ- } \\
\text { ation of dopants with the } \\
\text { interstitial clusters. } \\
-10^{17} \text { defects } / \mathrm{cm}^{3}\end{array}$ & $\begin{array}{l}\text { Break up of } V-V, V-P \text {, } \\
V-S b \text { complexes. Migra- } \\
\text { tion and annihilation of } \\
\text { vacancies. Divacancy } \\
\text { annealing (escape of } \\
\text { excess vacancies). }\end{array}$ & $\begin{array}{l}300^{\circ} \mathrm{C} \\
500^{\circ} \mathrm{C}\end{array}$ \\
\hline II I & $\begin{array}{l}\text { Break up of interstitial } \\
\text { clusters. Conversion } \\
\text { of interstitial clusters } \\
\text { to dislocation loops. } \\
\text { Segregation of dopants } \\
\text { atoins } \sim 1015 \text { defects } / \mathrm{cm}^{3}\end{array}$ & $\begin{array}{l}\text { Formation of vacancy } \\
\text { loops. Dislocation } \\
\text { attract interstitials } \\
\text { and vacnacy loops } \\
\text { shrink. }\end{array}$ & $\begin{array}{l}500^{\circ} \mathrm{C}- \\
700^{\circ} \mathrm{C}\end{array}$ \\
\hline IV & $\begin{array}{l}\text { Well developed interstitial } \\
\text { loops--hexagonal in stage, } \\
\text {-300A; } 1015 \text { defects/cm } \\
\text { inyolving about } 10^{15} \text { atoms/ } \\
\mathrm{cm}^{3} \text { Total number of ions } \\
\text { implanted }=2 \times 1018 / \mathrm{cm}^{3}\end{array}$ & $\begin{array}{l}\text { Vacancy loops a } 11 \\
\text { annihilated. }\end{array}$ & $-800^{\circ} \mathrm{C}$ \\
\hline
\end{tabular}




\subsection{Applications of the Model}

The model proposed above has two simple crnsequences which explain the experinental results of other workers. First, in the case where the damage layer is continuous a complex itructure of dislocation networks develop suggesting that the damaged layer anneals by epitaxial growth from small remaining islands of crystal. In such cases, for phosphorous, cumplete electrical activity of the dopant is achieved after a mild anneal of $600^{\circ} \mathrm{C}$ (Cihbons, 1972; Crowder and Morehead, 1969).

In terms of the present model the continuous amorphous layer relaxes the assumption that the volume of the crystal must remain unchanged. Consequently, the host interstitial atoms and the implanted dopant atoms can all find substitutional sites; additional atom Tayers can be formed during regrowth of the continuous amorphous layer. The observed dislocation tangles (Tamura et al., 1972) are consistent with this idea. The achievement of electrical activity is associated with the dopant becoming substitutional on a regular lattice site. Apparently, rather few phosphornus dopant atoms are attracted to the dislocation cores (Gibbons, 1969).

The second consequence of the model is the explanation of the contrast effects seen in Chapter IV. An example of this for loops in the foir plane is seen in Figs. 4.8 and 1.9. In Fig. 4.8 and Fig. 4.9 the effect of changing $g$ from +111 to -111 is shown. Notice how the loops appear dark in the inside image (4.8b) and faint in Fig. 4.8c. A similar effect is seen in weak-beam conditions Fig. 4.9.

This may be a structure factor contrast arising from the dopant atoms being attracted to the stacking faults associated with the 
loops. The sinilar effect observed in the perfect loop images first seen by Davidson and Booker (1970) might also be explained if some excess dopant concentration remains after unfaulting. The effect of this segregation on the displacement vector of the fault and on diffraction contrast is discussed below.

In Fig. 5.7, the (110) projection of a diamond cubic cell (Hornstra, 1968) is shown. The distance between the a layer and A layer is a/12[111]. An extrinsic fault is then made by inserting a double layer A-a into the perfect crystal. This is shown in Fig. 5.3. The vector is then $a / 3[111]$. Atoms whose sizes are close to that of silicon e.g., phosphorous could be incorporated in the stacking fault possibly complexed with vacancies. Such atoms are only weakly attracted to the dislocation core (Gibbons, 1972). However, the (111) direction in which the dotted bonds extended are expected to be soft and change to accommodate the absorbed atom (Fig. 5.3). The percentage of such atoms are expected to be 10-15\%. Since phosphorous is smaller than silicon the $c$ layer is expected to move slightly closer to $a$. The Burgers vector is no longer $a / 3[111]$ but $a / 3[111]--p \cdot a / 12[111]$. If $p=1, b=a / 4[11 !]$. Thus for small amounts of phosphorous $p$ is expected to be in the range $0<p<1$. The Burgers vector of a Frank loop with segregation may then be written as $a / 3[111]-a / g[111]$ or $a / x[111]$ with $x$ greater than three. The phosphorous atoms thus adsorbed may be electrically inactive as they are in a region of different crystal structure and may not provide the same electronic energy levels as they do in a regular site. Recently, Lee et al. (1973) observed a special spectrun in neutron irradiated silicon which he attributed to a possible phosphorous vacancy complex. The 


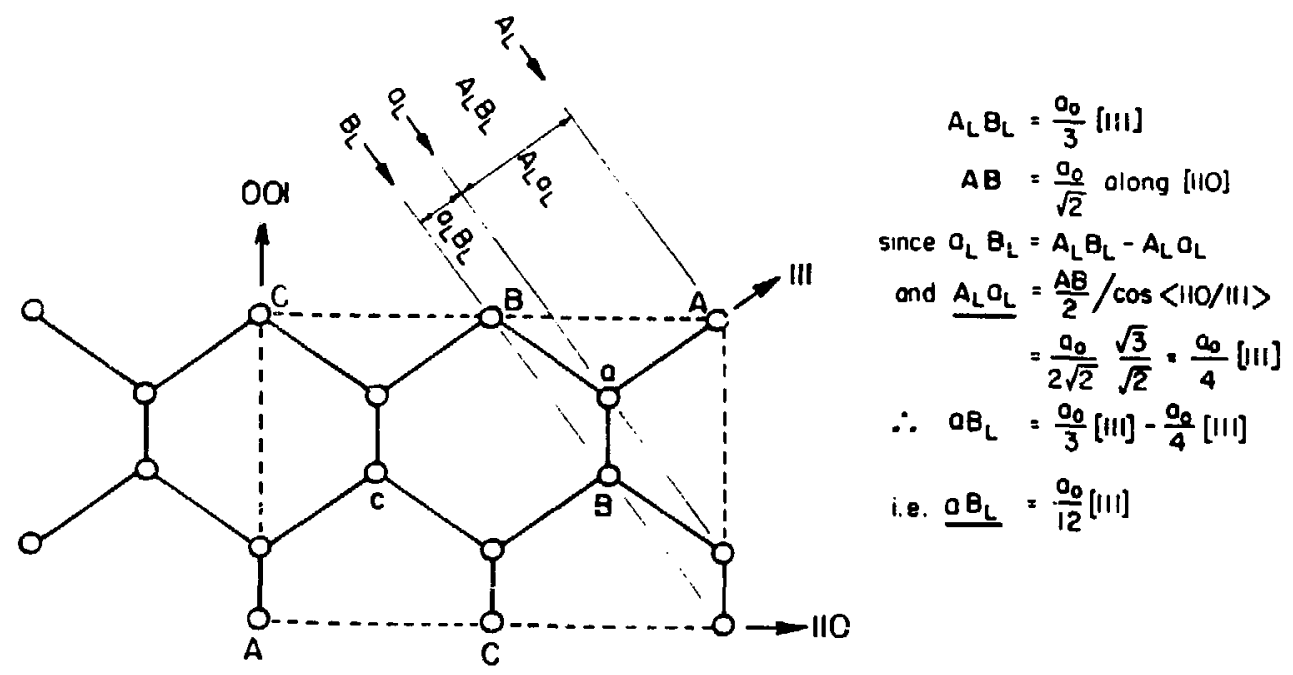

Fig. 5.6. The (150) projection of a diamond cubic cell (after Hornstra, 1968). The distance
between the a and $B$ layer, $a B_{1}$, is shown to be $\left.a / \% 2[11)\right]$. 
AOCAB̈ACABC

1

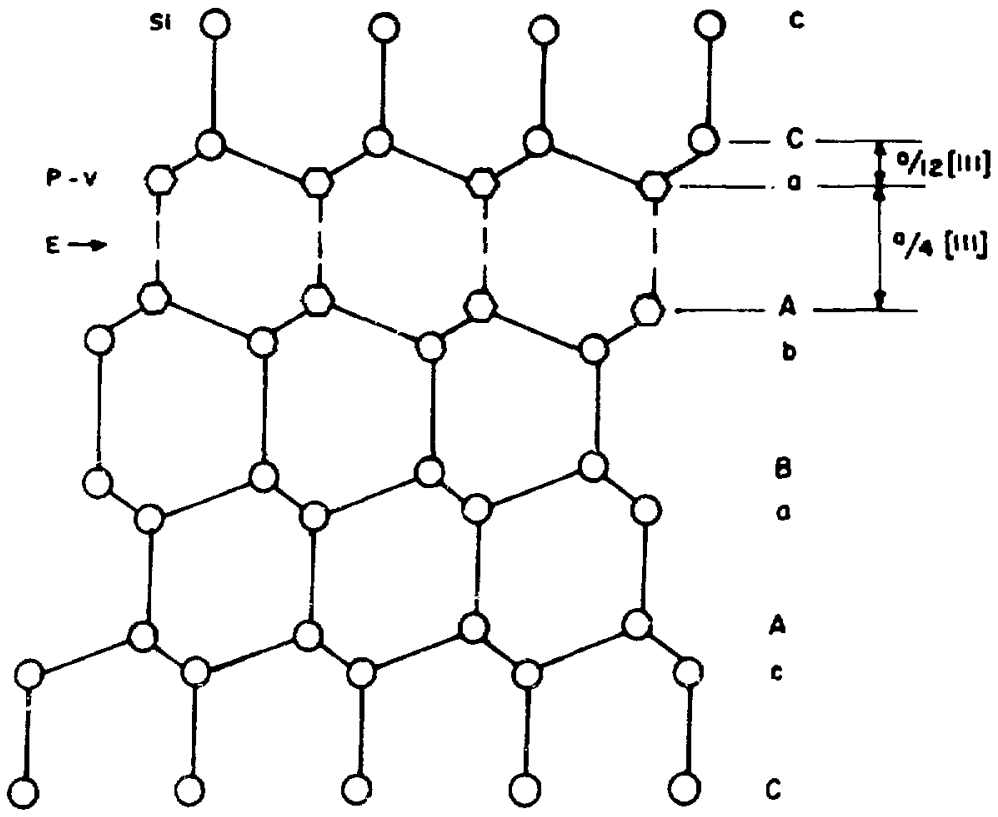

O Phosphorous Weoncy Complex $(P-V)$

- - Bonds Ratoxed in the <III> Oirection

Extrinsic Foult

$X B L 747-668 i$

Fig. 5.7. An interstitial fault (E) caused by the insertion of an extra A-a layer. The dotted bonds in the (iii) direction are "soft" and could accomodate a phosphoruus-vacancy complex instead of a silicon 3 tom. This would result in a small change of the fault vector from $a / 3[111]$ to $a / x[111], x>3$. 
defect has an extra localized electron and the phosphorous atom is compensated.

In terms of the model presented in this chapter, this p-vacancy complex could segregate to the hexagonal atom positions on the fault as shown in fig. 5.3. The concequent relaxation of the bonds ir. the [111] direction yields a fault vector of a/x[111] with $x>3$ as explained previously.

The contrast feature in the Frank loops shown in Figs. 4.8 and 4.9 is explicable in terms of the dopants segregating on the stacking fault. The contrast effect in the prefect loops is explicable on the basis of the dopant vacancy complexes remaining after the Frank loops have unfaulted. This reaction is expected to proceed as

$$
a / 3[111]=a / y[111]+a / 6[11 \overline{2}]=a / 2[110]-a / y[111] .
$$

The perfect loops then have a small displacement "fault" of a/y[111]. Such a displacement acts effectively as a structure factor contrast would arise. 


\subsection{Conclusions}

A nodel that explains the annealing process of ion implantation damage in silicon and the presence of the experimentally observed interstitial defects has been developed. It is suggested that submicroscopic interstitial clusters form for the case of subcritical damage. These occl." in addition to vacancy clusters consistent with the fact that Frankel pairs are produced by the bombarding ions. A four stage process is developed with accounts for the presently known behavior of vacancies. Two effects are used to develop the model. The first is the slightly greater interaction becween the interstitial and the dislocation line than that between the vacancy and the dislocation. This increases the chances of survival of interstitial loops over vacancy lonps. The second is that discontinuous damage does introduce any lattice sites even when it recrystallizes. Therefore, the implanted dopants displace $10^{18}$ atoms $/ \mathrm{cm}^{3}$ during annealing which can account for the interstitial defects.

The poor electrical activity of the $\mathrm{P}^{+}$ions in the $2 \times 10^{14}$ range (uiscontinuous damage range) which cannot be explained on the basis of their interaction with the dislocation core is explained on the basis of their interaction which the stacking fault within the Frank loops. This segregation alsc may explain the anomalous contrast effects observed in the electron microscope images of these and perfect loops. 
"Between you and them is distance Uncertainty--

Care".

D. J. Hamnarsjkold

\section{ACKNOWL EOGEMENTS}

Not merely more metallurgy but an attitude to life and thought I have learned from Professor Washburn's discerning guidance. Any competence the electron microscopy may show is probably traceable to Professor G. Thomas and his unflagging goading to try new methods. To many I owe tharks for giving me their help and sharing with she their humanity--to many to name individually--those not to be amittes are the Merriams, the Howitts, Margaret Robson and Thorvald Astrup. To Patti Fenton I owe instructive distraction and the human lesson. We thank Dr. V. G. K. Reddi of Fairchild R \& D Divisicn, Palo Alto, CA for kindly supplying the ion-implanted samples. My thanks to Jean Wolslegel for the patient typing and to the Energy Research and Development Adninistration for financial support. 


\section{REFERENCES}

T. 0. Baldwin, The Effects of Fast Neutron Irradiation at Ambient Temperature on the Lattice Parameter of Silicon and Germanium. Phys. Rev. 21, 901 (1968).

W. L. Bell and G. Thomas, Useful Properties of Dark Field Images. Phys. Stat.. Sol. 12, 843 (1965).

R. W. Bicknell, The Distribution of Condensed Defect Structures Formed in Annealing Boron-implanted Silicon. Proc. Roy. Soc. (London) 311A, 75 (1969).

R. W. Bicknell, weak-beam Observation of Dislocation Loops in Silicon J. Microscopy 98, 165 (1973).

R. W. Bicknell,, R. M. Allen, Correlation of Electron Microscope Studies with the Electrical Properties of Boron Implanted Silicon, Radiation Effects, $\underline{6}, 45$ (1970).

L. T. Chadderton and F. H. Eisen, On Annealing of Damage Produced by $\mathrm{B}^{+}$Ion Implantation in Silicon Single Crystals, Radiation Effects 7., 129 (1971).

L. J. Chen, K. Seshan, G. Thomas, Contrast and Resolution of Small Dislocation Loops in HiEM. Phys. Stat. Sol. (to be published, 1975).

L. J. Chen, Theoretical and Experimental Analysis of Crystal Defects with Particular Emphasis to Silicon (Ph. D. Thesis), LBL-3179, May, 1974.

L. J. Cheng, T. C. Corelli, J. W. Corbett and G. D. Watkirs, 1.8-, 3.3-, 3.9u Bands in Irradiated Silicon: Correlations with the Divacancy. Phys. Rev. 152(2), 761 (1966). 
B. L. Crowder, frivate Communication, 1974.

B. L. Cruwder, F. F. Morehead, Jr., Annealing Charateristics of n-type Dopants in Ion-implanted Silicon. Applied Phys. Letters 14:10 $313(1969)$.

B. L. Crowder and R. S. Title, The Distribution of Damage Produced by Ion-Implantation of Silicon at Room Temperature. Radiation Effects 6, $63(1970)$.

D. J. H. Cockayne, I. L. F. Ray and M. J. Whelan, Investigation of Dislacation Strain Fialds Using Weak Beams. Philosophical Magazine 20, 1265 (1969).

D. F. Daley and K. A. Pickar, EPR in Ion Implanted Silicon, Appl. Phys. Lett. 15, 267 (1969).

5. M. Davidson and G. R. Booker, Damage Produced by Ion Impiantation in Silicon, Radia. Eff. $\underline{6}, 45$ (1970).

J. W. Edington and R. E. Smallman, Faulted Dislocation Laops in Quenched Aluminium, Philosophical Magazine 11, 1109 (1965).

E. P. Ernisse, Sensitive Techniques for Studying lon-Implantation Damage, Applied Physics Letters 18, 581 (1971).

J. F. Gibbons, Ion-Implantations in Semiconductors, Pt. I, Proceedings IEEE 56, 3, 295 (1968).

J. F. Gibbons, ibid. Part I1. Proceeding IEEE 60 (9), 1067 (1972).

J. F. Gibbons, On the Effectiveness of Dislocation Loops for the Adsorption of Implanted Ions, kadiation Effects 6 , 313 (1970).

H. M. Gibson, F. W. Martin, R. Stensgaard, F. Plamgren Jensen, N. I. Meyer, G. Galster, A. Johnsen and J. S. Olsen, Electrical and Physical Measurements on Silicon Implanted with Channeled and 
Non-Channeled Dopant Ions, Canadian J. Phys. 46, 675 (1968). P. B. Hirsch, A. Howie, R. B. Nicholson, D. W. Pashley, M. J. Whelan, Electron Microscopy of Thin Crystels (Butterworths, 1965a), p. 205.

J. P. Hirth and J. Lothe, Theory of Dislocations (McGraw Hill. Inc., 1968).

J. Hornstra, Dislocations in the Diamond Lattice, J. Phys. Chem. Sol. $\underline{5}, 129$ (1958).

A. Howie, 2. S. Basinski, Approximations of the Oynomicel Theory of Diffraction Contrast, Philosophical Magazine 1], 1039 (1968).

C. J. Humphreys, The Optimum Voltage in Very High Vultage Electron Microscopy, Philosophical Magazine 25, 1459 (1972).

C. J. Humphreys, L. E. Thomas, J. S. Lally, R. M. Fisher, Maximizinq the Penetration in High Voltaqe Electron Microscopy, Philosophical Magazine , 87 (1971).

M. L. Jenkins, D. J. H. Cockayne and M. J. Whelan, The Geometry of Siall Frank Loops, J. Microscopy 98,155 (1973).

P. M. Kelley and R. H. Blake, The Symmetric Weak Beam Method and Its Application to Dislocation Loop Analysis, Philosophical Magazine $\underline{28}, 475$ (1973).

Y. H. Lee, Y. M. Kim, J. W. Corbett, New EPR Spectra in Irradiated Silicon, Radiation Effects 15, 78 (1972).

P. K. Madden, Structural and Electrical Studies of Ion-Implanted Semiconductors ('h. D. Thesis), University of Oxford (1974).

M. D. Mathews, Electrical and Electron Microscopy Observations on Dejects in Ion-implanted Silicon, Rad. Eff. 11:3-4, 167 (1971). 
J. W. Mayer, Ion Implantation Semi-conductors: Lattice Disorder and Electrical Effects, JEEE Trans. 15(6), 10 1968).

J. H. Mayer, Ion Implantation - Lattice Disorder, Radia. Eff. 8, 259, (1971).

D. Mazey, R. J. Nelson and A. S. Barnes, Observation of Inz-boabardment Damage on Silicon, Philosuphical Magazine 17, 1145:968).

F. F. Morahead, Jr. and B. L. Crowder, A Model for the Formation of Amorphous Si by Ion-t mbardment, Radia. Eff. 6, 27 (1370).

R. 5 Nelson, The Physicai State of Ion-implanted Soijds. Proc. Roy. Soc. A311, \$3 (1969).

‥ R. Noonan, C. A. Kirkpatrick and B. G. Streetman, Low Temperature Photoluminescena from Boron lon-implante: Silicon. Radia. Eff. 2l, $225(1974)$.

R. Osiecki and G. Thomas, Enhanced fesolution of Dislocation Imaginu at Hiqh Voltaqes. Proc. 29th Annual Conference, Baton Rougo, LA, (1971), p. 178.

J. R. Parsons, Conversion of Cirystalline Gemanium to Amorphous Germanium: by Ion-Bombirdment, Philosophical Magazine 12, 1159 (1965).

R. C. Perrin and B. L. Eyre, The Application of Weak Beam Imaging to Studies of Small Dislocation Loops, J. Microscopy 98(2), 200 (1973).

A. Seeger, Investigation of Point Defects in Silicon and Germanium by Non-irradiation Techniques, Radia. Eff. 9, 15 (1971).

A. Seeger and K. P. Chik, Diffusion Mechanisms and Point Defects in Silicon and Germanium, Phys. Stat. Sol. 29, 455 (1968).

K. Seshan and J. Washburn, On the Precipitation of Phosphorous in IonImplanted Silicon, Radia. Eff. 14, 27l (1972). 
K. Sesilan, Non-Conventional Electron Microscopy in Small Defect Characterization, Proceedings 32nd Annual EMSA Meeting, Claitor PubTishers, Baton Rouge, LA, 1974.

K. Seshan and J. 'iashburn, Some New Results in the Characterization of Defects in Ion-impianted Silicon, Radia. Eff. (1975).

H. J. Stein, Depth in Silicon. Concepts and Correlation, Radiation Effects $\underline{9}, 175$ (1971).

H. J. Stein, F. L. Vook and J. A. Borders, Direct Evidence of Divacancy Formation in Silicon by Ion-implantation, Appl. Phys. Lett. 14, 328 (1959).

G. D. Watkins, F.adiation Damage in Semiconductors (Donod de Paris, 1965), o. 97.

W. K. Wu, J. Washburn, Identification of Interstitial and Vacancy Type Dislocation Locps in Ion-implanted Silicon, J. Appl. Phys. $\underline{45}$, $1085(1974)$. 